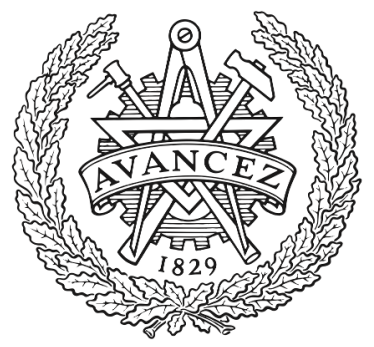

CHALMERS

UNIVERSITY OF TECHNOLOGY

\title{
A numerical investigation of curve squeal in the case of constant wheel/rail friction
}

Downloaded from: https://research.chalmers.se, 2023-04-26 09:11 UTC

Citation for the original published paper (version of record):

Pieringer, A. (2014). A numerical investigation of curve squeal in the case of constant wheel/rail friction. Journal of Sound and Vibration, 333(18): 4295-4313.

http://dx.doi.org/10.1016/j.jsv.2014.04.024

N.B. When citing this work, cite the original published paper. 


\title{
A numerical investigation of curve squeal in the case of constant wheel/rail friction
}

\author{
A. Pieringer* \\ Division of Applied Acoustics/CHARMEC, Chalmers University of Technology, \\ 41296 Göteborg, Sweden
}

\begin{abstract}
Curve squeal is commonly attributed to self-excited vibrations of the railway wheel, which arise due to a large lateral creepage of the wheel tyre on the top of the rail during curving. The phenomenon involves stick/slip oscillations in the wheel/rail contact and is therefore strongly dependent on the prevailing friction conditions. The mechanism causing the instability is, however, still a subject of controversial discussion. Most authors introduce the negative slope of the friction characteristic as source of the instability, while others have found that squeal can also occur in the case of constant friction due to the coupling between normal and tangential dynamics. As a contribution to this discussion, a detailed model for high-frequency wheel/rail interaction during curving is presented in this paper and evaluated in the case of constant friction. The interaction model is formulated in the time domain and includes the coupling between normal and tangential directions. Track and wheel are described as linear systems using pre-calculated impulse response functions that are derived from detailed finite element models. The non-linear, non-steady state contact model is based on an influence function method for the elastic half-space. Real measured wheel and rail profiles are used. Numerical results from the interaction model confirm that stick/slip oscillations occur also in the case of constant friction. The choice of the lateral creepage, the value of the friction coefficient and the lateral contact position on the wheel tread are seen to have a strong influence on the occurrence and amplitude of the stick/slip oscillations. The results from the interaction model are in good qualitative agreement with previously published findings on curve squeal.
\end{abstract}

Key words: curve squeal, wheel/rail interaction, time-domain, squeal mechanism, friction, stick/slip

* Tel.: + 46 31772 2209; fax: +46 317722212.
Email address: astrid.pieringer@chalmers.se (A. Pieringer). 
Curve squeal is a highly disturbing tonal sound generated by a railway vehicle negotiating a sharp curve. This type of noise is commonly attributed to self-excited vibrations of the railway wheel [1].

Since Rudd [2] in accordance with an earlier paper by Stappenbeck [3] discarded longitudinal creepage and flange rubbing as relevant causes for curve squeal, it is widely accepted that curve squeal arises from stick/slip behaviour due to lateral creepage of the wheel tyre on the top of the rail. The actual mechanism of the instability is however still a controversial topic. Rudd [2] introduced the negative slope of the friction characteristic (i.e. decreasing friction for increasing sliding velocity) as the source of the instability and most subsequent models have adopted this approach [4-11]. The existence of a 'falling' regime of the friction characteristic in wheel/rail contact is experimentally well substantiated, see e.g. $[8,12-16]$. As friction is however difficult to measure, it is inevitable to make assumptions about the exact shape of the friction characteristic in models for curve squeal. Correspondingly, many different friction curves have been used in the literature.

From a mathematical point of view, the instability can also be explained by the coupling between normal and tangential dynamics, leading to the nonsymmetry of the system's stiffness matrix [17]. This mechanism is exemplified by Hoffmann et al. [18] with a model having two degrees of freedom. Glocker et al. [19] recently presented a curve squeal model that shows stick/slip oscillations in the case of a constant friction coefficient. They identified one axial mode with zero nodal circles and two radial modes of the wheel, which occur at similar frequencies, as essential for the squeal mechanism. Simulation results showing stick/slip in the case of constant friction have also been reported by Ben Othman [20] and Brunel et al. [10]. Some experimental evidence that squeal occurs in the case of constant friction has been presented by Koch et al. [21], who performed measurements on a test rig. Also the conditions at some sites in the Australian railway network suggest the existence of an alternative squeal mechanism [22].

It is possible that both squeal mechanisms coexist in practice and this might be one reason why some models (for certain parameter combinations and initial conditions) show squeal in the case of a constant friction coefficient while others do not. Another reason is certainly that the results of all the models presented depend on model assumptions and the level of model complexity included. Curve squeal, which is an intrinsically non-linear and transient phenomenon, still poses a challenge in modelling. Frequency domain models can predict which modes are prone to squeal, but models aiming to predict squeal amplitudes have to be formulated in the time-domain. Due to the required computational effort of time-domain solutions, it is usually necessary to simplify wheel, rail and contact dynamics, and, by consequence, the models might 
not include all the important features of the phenomenon.

As curve squeal is closely related to the excitation of wheel modes, most authors of time-domain models opt for a detailed wheel model. A modal model of the railway wheel or wheelset derived from a finite element (FE) model has e.g. been considered in the models $[4,5,9,10,19,23]$. The rail dynamics has, however, only been included in a few time-domain models [4,5,23]. Huang et al. [23] found that the simulation results change considerably if the rail is assumed to be rigid, while Périard [5] concluded that there was no significant influence of the rail dynamics on squeal during steady-state curving. The knowledge about the influence of different contact models on the simulation results is still fairly limited. Most models use analytical formulas to represent the creep force / creep relation, which can only partly represent the non-linear processes in the contact zone. Périard [5] included a modified version of Kalker's steady-state contact model FASTSIM [24] in his squeal model. To the knowledge of the authors, so far no transient, three-dimensional contact model has been used in a squeal model.

The aim of the work presented in this paper is to contribute to the modelling and understanding of curve squeal by proposing a detailed time-domain model for dynamic wheel/rail interaction that considers the coupling between normal and tangential directions. Thus, the model covers the generation of squeal noise in the wheel/rail contact, which is seen as the central problem in squeal prediction, but does not include sound radiation from the wheel. The computational effort in the wheel/rail interaction model is reduced by representing vehicle and track by impulse response functions derived from detailed FE models, which are calculated in advance. This technique, which has proven efficient for instance in the area of tyre/road noise [25] and in vertical wheel/rail interaction [26], makes it possible to include a three-dimensional, non-linear and transient contact model that is solved at each time step in the interaction model. This interaction model has shown stick/slip oscillations in combination with a velocity-dependent friction coefficient $[27,28]$. As a contribution to the discussion about the squeal mechanism, the work presented in this paper is limited to constant friction. After a description of the wheel/rail interaction model in Section 2, a parameter study is presented in Section 3 in order to investigate whether instabilities occur due to the coupling between normal and tangential dynamics.

\section{Wheel/rail interaction model}

The wheel/rail interaction model is primarily intended for quasi-static curving of the leading inner wheel in a railway bogie. The model relies on the wheel/rail contact position and the angle of attack of the wheelset (i.e. the lateral creepage) as given input parameters. These parameters can be pre- 
calculated with a vehicle dynamics program.

Fig. 1 shows the reference frame of the wheel/rail interaction model. The $x$-direction (1-direction) is the rolling direction along the rail. The lateral direction is the $y$-direction (2-direction) pointing towards the field side of the wheel. The vertical (or normal) $z$-coordinate (3-coordinate) is pointing into the rail. This reference frame is moving with the nominal contact point along the rail.

The detailed FE models used for wheel and track include the longitudinal, lat-

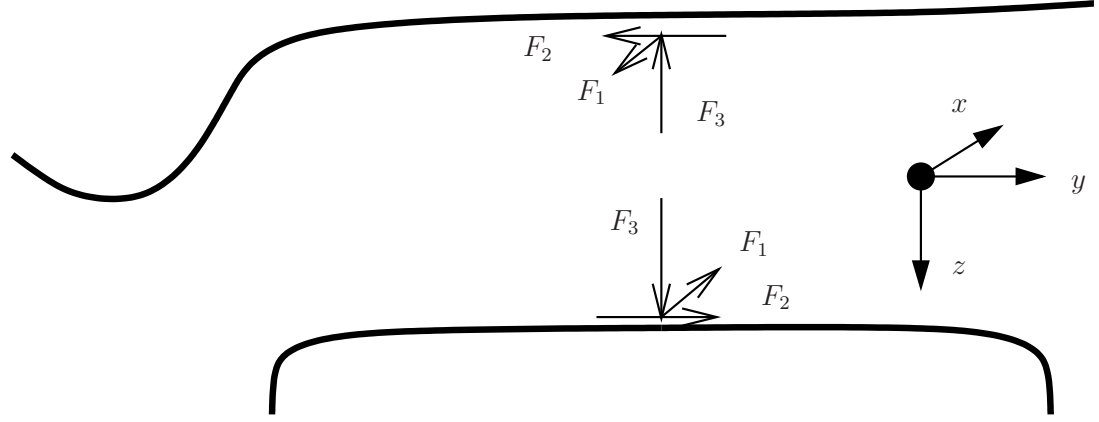

Fig. 1. Reference frame of the interaction model.

eral and vertical dynamics. Although all three directions could also be included in the wheel/rail interaction model, where wheel and track are represented by impulse response functions calculated from these FE models, the present study is limited to vertical and lateral dynamics of wheel and track. The wheel/rail contact is however treated as fully three-dimensional.

\subsection{Wheel model}

The vehicle is represented by a single flexible wheel, which is modelled by axisymmetric finite elements using a commercial finite element software. Fig. 2 shows the meshed cross-section of the selected wheel, which is a C20 metro wheel of diameter $780 \mathrm{~mm}$. A rigid constraint is applied at the inner edge of the hub, where the wheel would be connected to the axle. The material data of the wheel are listed in Table 1.

With this FE model, the eigenfrequencies (see Table 2 and Fig. 3) and corresponding eigenmodes have been calculated up to $7 \mathrm{kHz}$. The eigenmodes are classified according to their predominant motion in axial, radial and circumferential modes, which have $n$ nodal diameters and $m$ nodal circles [1]. The axial modes will be denoted $(n, m, a)$. As $m>0$ does not occur for radial and circumferential modes in the frequency range of interest, they will be referred to as $(n, \mathrm{r})$ and $(n, \mathrm{c})$, respectively. Examples of two axial modes and one radial 


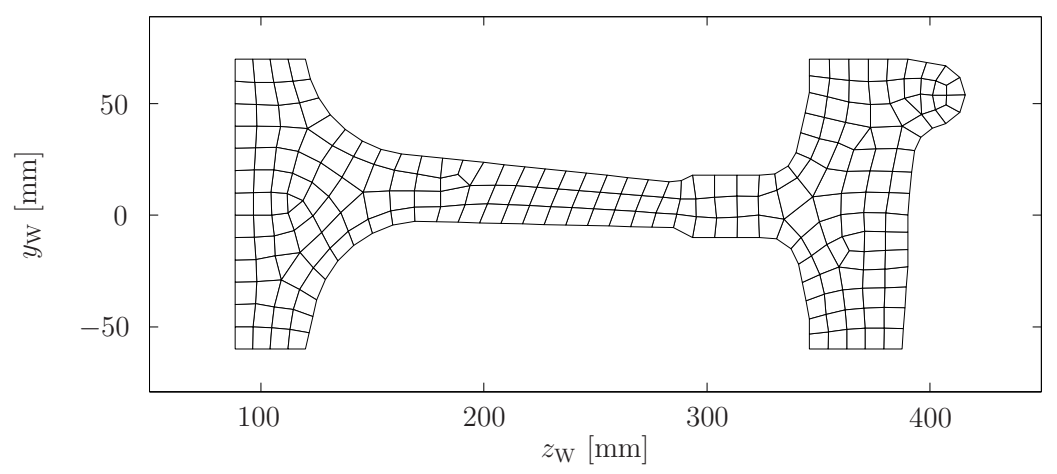

Fig. 2. FE mesh of the C20 wheel cross-section.

Table 1

Material properties of the wheel and the continuously supported rail

\begin{tabular}{llll}
\hline & Wheel & Rail & Pad \\
\hline Young's modulus & $207 \mathrm{GPa}$ & $207 \mathrm{GPa}$ & $4.8 \mathrm{MPa}$ \\
Poisson's ratio & 0.3 & 0.3 & 0.45 \\
Density & $7860 \mathrm{~kg} / \mathrm{m}^{3}$ & $7860 \mathrm{~kg} / \mathrm{m}^{3}$ & $10 \mathrm{~kg} / \mathrm{m}^{3}$ \\
Damping loss factor & see Eq. (1) & 0.01 & 0.25 \\
\hline
\end{tabular}

mode are shown in Fig. 4. The omission of the axle is known to lead to errors in eigenfrequency and mode shape for modes with $n \leq 1$, but has a negligible effect on higher-order modes [1]. As especially higher-order axial modes (with $n \geq 2$ ) have been found to be important for curve squeal [1,9], this is not seen as critical for the investigation of squeal noise.

The eigenmodes are assigned a modal damping ratio $\zeta$ using the approximate values proposed by Thompson [1]:

$$
\zeta=\left\{\begin{array}{l}
10^{-3} \text { for } n=0 \\
10^{-2} \text { for } n=1 \\
10^{-4} \text { for } n \geq 2
\end{array} .\right.
$$

The mode $(1, r)$ is assigned a damping ratio of 1 , since this mode appears too strongly in the frequency response function, when the influence of the axle is disregarded [1]. These damping ratios are used as a first approximation. Considering the importance of wheel damping for the occurrence of squeal, measured modal damping ratios should be used for the investigation of a specific squeal problem in a specific curve.

After determining the contact point on the wheel (see Section 2.3), the wheel receptances in the corresponding node are calculated by modal superposition. In addition to the modes of the flexible wheel calculated with the FE model, 
Table 2

Eigenfrequencies $f$ of the $\mathrm{C} 20$ wheel up to $7 \mathrm{kHz}$ calculated with the FE model. The modes are classified according to mode type, number of nodal diameters $n$ and number of nodal circles $m$.

\begin{tabular}{|c|c|c|c|c|c|c|c|c|c|}
\hline \multicolumn{10}{|c|}{ Axial modes } \\
\hline \multicolumn{10}{|c|}{ Zero nodal circles $(\mathrm{m}=0)$} \\
\hline n [-] & 0 & 1 & 2 & 3 & 4 & 5 & 6 & 7 & 8 \\
\hline $\mathrm{f}[\mathrm{Hz}]$ & 332.8 & 243.2 & 429.9 & 1143 & 2058 & 3071 & 4131 & 5216 & 6316 \\
\hline \multicolumn{10}{|c|}{ One nodal circle $(\mathrm{m}=1)$} \\
\hline $\mathrm{n}[-]$ & 0 & 1 & 2 & 3 & 4 & 5 & 6 & 7 & \\
\hline $\mathrm{f}[\mathrm{Hz}]$ & 1924 & 2089 & 2585 & 3193 & 3881 & 4635 & 5454 & 6343 & \\
\hline
\end{tabular}

Two nodal circles $(\mathrm{m}=2)$

$\begin{array}{lcccccc}\text { n }[-] & 0 & 1 & 2 & 3 & 4 & 5 \\ \text { f }[\mathrm{Hz}] & 4177 & 4237 & 4417 & 4872 & 5547 & 6406\end{array}$

\begin{tabular}{lcccccccc}
\hline \multicolumn{1}{l}{ Radial modes $(\mathrm{m}=0)$} \\
\hline $\mathrm{n}[-]$ & 0 & 1 & 2 & 3 & 4 & 5 & 6 & 7 \\
$\mathrm{f}[\mathrm{Hz}]$ & 3625 & 1586 & 2243 & 2834 & 3536 & 4350 & 5268 & 6269 \\
\hline
\end{tabular}

Circumferential modes $(\mathrm{m}=0)$

\begin{tabular}{cccc}
\hline $\mathrm{n}[-]$ & 0 & 1 & 2 \\
$\mathrm{f}[\mathrm{Hz}]$ & 722.0 & 3886 & 5228
\end{tabular}

the rigid body modes of the complete wheelset including the primary suspension are considered. Notably translation in vertical direction $(11.1 \mathrm{~Hz})$, translation in lateral direction $(14.4 \mathrm{~Hz})$ and rotation in the vertical/lateral plane $(16.5 \mathrm{~Hz})$ are included in the modal summation. Fig. 5 shows as examples the vertical and lateral point receptances and the vertical/lateral cross-receptance for the node at $y_{\mathrm{W}}=-32 \mathrm{~mm}$ on the wheel tread. This node corresponds to the nominal simulation case in Section 3.

The impulse response functions (or Green's functions) of the wheel, $g_{i j}^{\mathrm{W}}$, are then obtained by inverse Fourier transform from the wheel receptances, $G_{i j}^{\mathrm{W}}$ :

$$
g_{i j}^{\mathrm{W}}(t)=\mathscr{F}^{-1}\left(G_{i j}^{\mathrm{W}}(f)\right), \quad i, j=2,3 .
$$

The subscripts $i$ and $j$ denote the excitation and response directions, respectively. The first $0.4 \mathrm{~s}$ of the impulse response functions corresponding to the receptances from Fig. 5 are presented in Fig. 6. As the wheel is very lightly 


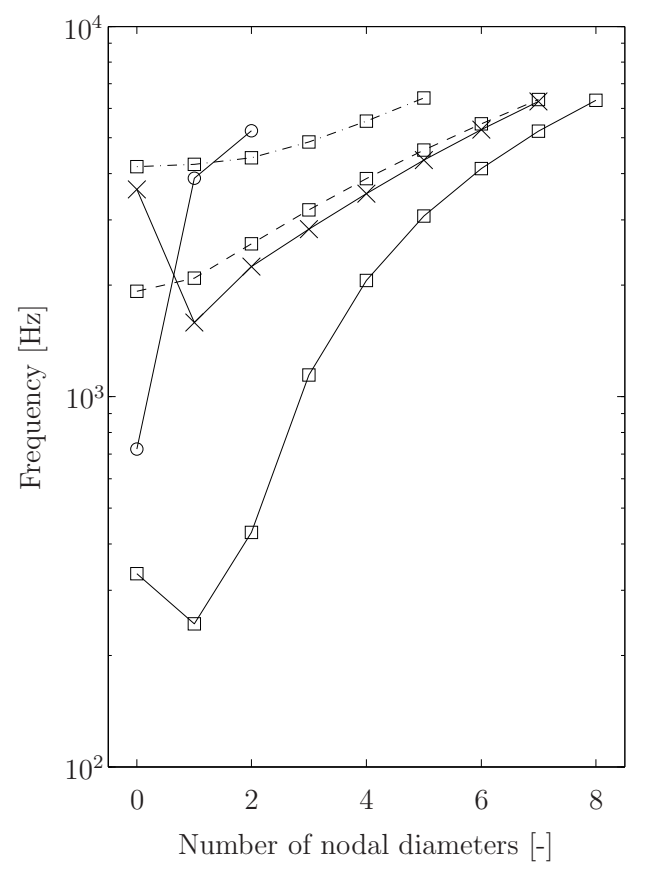

Fig. 3. Eigenfrequencies of the $\mathrm{C} 20$ wheel up to $7 \mathrm{kHz}$ calculated with the $\mathrm{FE}$ model: axial modes $(\square)$, radial modes $(\times)$ and circumferential modes $(\circ)$ with zero nodal circles $(-)$, one nodal circle $(---)$ and two nodal circles $(-\cdot-)$.

(a)

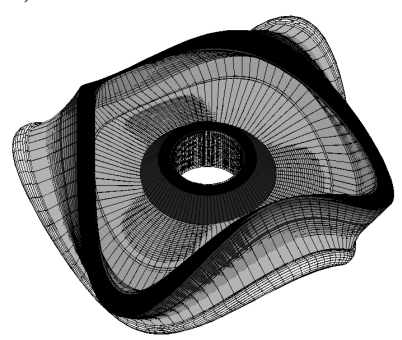

(b)

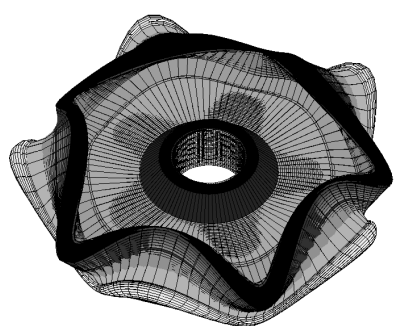

(c)

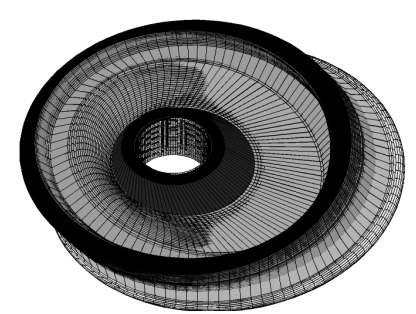

Fig. 4. Examples of wheel modes: (a) axial mode $(3,0, a)$; (b) axial mode $(5,0, a)$; (c) radial mode $(1, \mathrm{r})$.

damped, the impulse responses decrease slowly and long signals have to be considered. The total length of the impulse response signals taken into account is $20 \mathrm{~s}$.

In the interaction model, the lateral and vertical displacements of the wheel at the contact point, $\xi_{2}^{\mathrm{W}}(t)$ and $\xi_{3}^{\mathrm{W}}(t)$, are calculated by convoluting the contact forces $F_{2}$ and $F_{3}$ with the Green's functions

$$
\xi_{j}^{\mathrm{W}}(t)=-\int_{0}^{t} \sum_{i=2}^{3} F_{i}(\tau) g_{i j}^{\mathrm{W}}(t-\tau) \mathrm{d} \tau, \quad j=2,3 .
$$



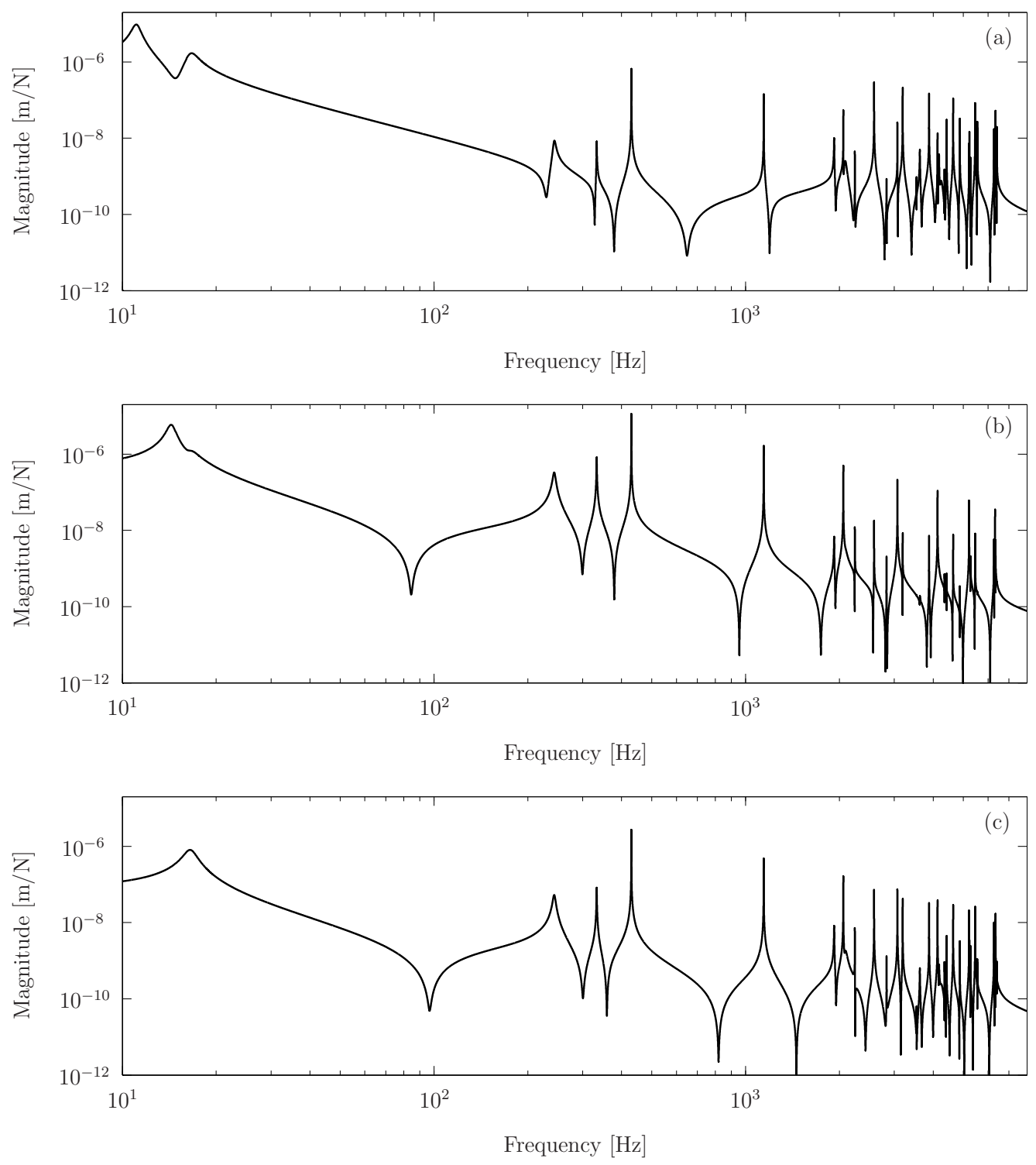

Fig. 5. Magnitudes of the wheel receptance at $y_{\mathrm{W}}=-32 \mathrm{~mm}$ on the tread: (a) vertical point receptance, (b) lateral point receptance, (c) vertical/lateral cross receptance.

The influence of wheel rotation is neglected.

\subsection{Track model}

The track model consists of one continuously supported rail of type BV50 (a common Swedish rail type) and is built with waveguide finite elements using the software package WANDS [29]. This model takes advantage of the twodimensional geometry of the rail having a constant cross-section in $x$-direction, but nonetheless considers the three-dimensional nature of the vibration by as- 

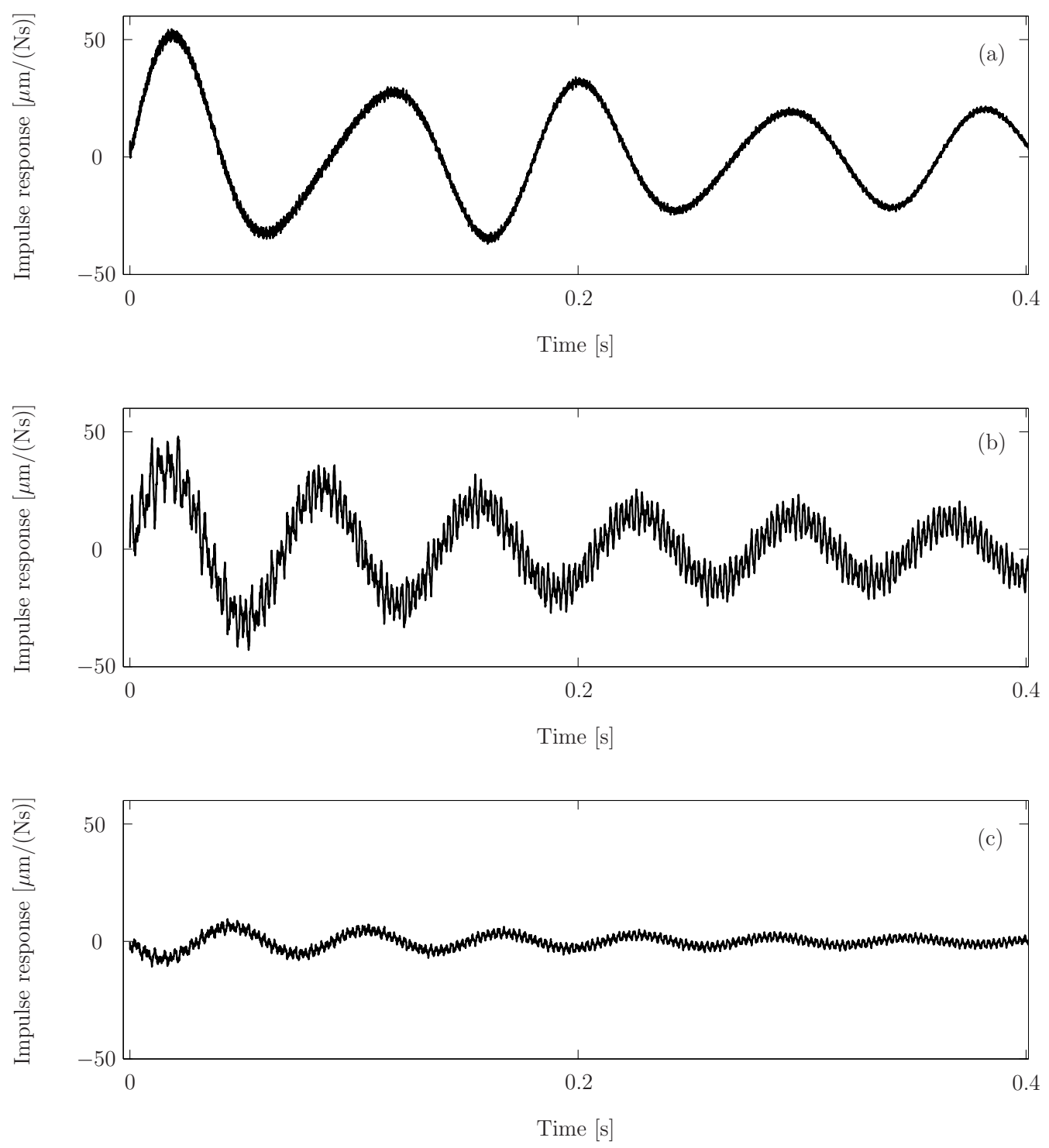

Fig. 6. Impulse response functions of the wheel calculated at $y_{\mathrm{W}}=-32 \mathrm{~mm}$ on the tread : (a) vertical, (b) lateral, (c) vertical/lateral.

suming a wave-type solution along the rail. Cross-sectional deformations of the rail, which are important for high-frequency applications, are taken into account.

The waveguide finite element (WFE) mesh of the continuously supported rail, which consists of eight-noded isoparametric quadrilateral elements, is presented in Fig. 7. The material data of rail and support, which are chosen similar to the data given in [29], are listed in Table 1. The vertical stiffness of the continuous support corresponds to soft rail supports.

The equations of the WFE model are presented by Nilsson et al. in [29]. Only a short summary is given here. 


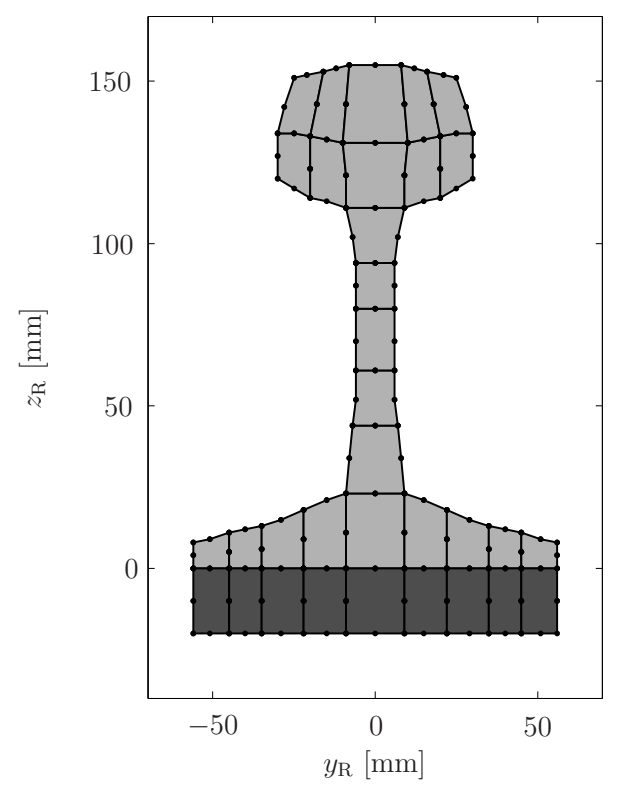

Fig. 7. WFE mesh of the BV50 rail.

The basic principle of the WFE method is that the displacement $\mathbf{u}=\left[u_{x}, u_{y}, u_{z}\right]^{\mathrm{T}}$ - in the $x$-, $y$ - and $z$-directions - in one waveguide finite element is formulated as

$$
\mathbf{u}=\mathbf{N}(y, z) \hat{\mathbf{u}}(x),
$$

where $\hat{\mathbf{u}}$ is the vector of nodal displacements and $\mathbf{N}(y, z)$ are two-dimensional (2D) FE shape functions; i.e. a $2 \mathrm{D}$ mesh is sufficient to describe the threedimensional structure.

In the same manner as for standard FE models, the complete WFE model is assembled from the formulation on element level. For free harmonic motion, the equations of the assembled WFE model represent an eigenvalue problem in wavenumber $k$ at a given frequency $\omega$. The eigenvectors $\tilde{\mathbf{U}}_{n}$ correspond to cross-sectional wave shapes. The eigenvalues $k_{n}$ obtained as complex-valued wavenumbers describe propagation and decay of the waves along the rail. For an implicit time dependence $\mathrm{e}^{\mathrm{i} \omega t}$, the amplitude of a free harmonic wave propagating in the positive $x$-direction is thus described by

$$
\hat{\mathbf{U}}_{n}(x)=\tilde{\mathbf{U}}_{n} \mathrm{e}^{-\mathrm{i} k_{n} x},
$$

where $\hat{\mathbf{U}}_{n}$ is the global displacement vector containing all degrees of freedom in the cross-section. The eigenvalues are represented in Fig. 8 in the form of the dispersion relation. The wave shapes belonging to the different wave types in Fig. 8 are shown in Fig. 9 for the case $k_{n}=1 \mathrm{rad} / \mathrm{m}$.

The response to forced excitation is obtained by superposing the contributions from the different waves. For propagation in the positive $x$-direction, the global displacement vector $\hat{\mathbf{U}}_{0}$ obtained due to a harmonic point force at $x=0$ 


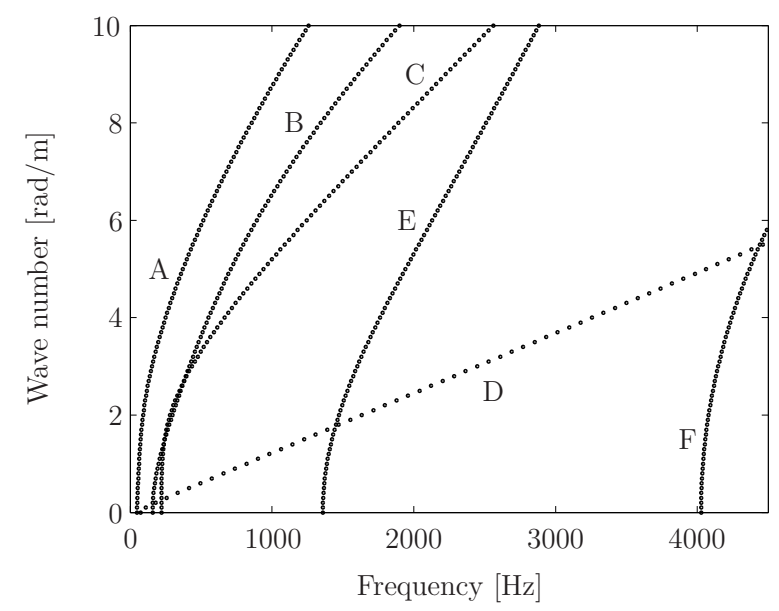

Fig. 8. Dispersion relation for the continuously supported rail. Wave types: (A) Lateral bending wave, (B) Vertical bending wave, (C) Torsional wave, (D) Longitudinal wave, (E) Web bending wave 1, (F) Web bending wave 2 .

(a)

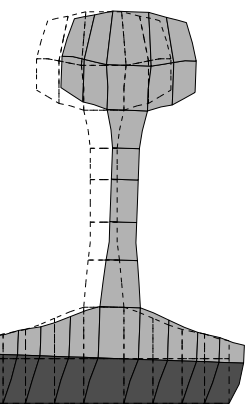

(d)

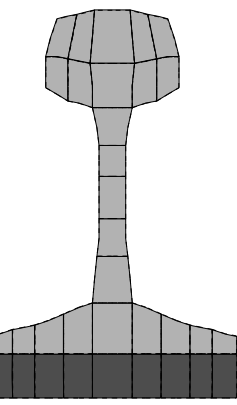

(b)

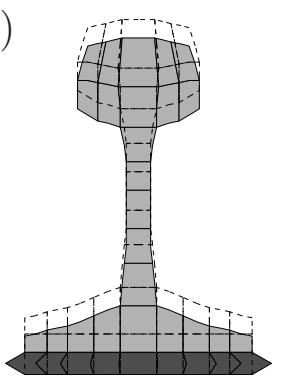

(e)

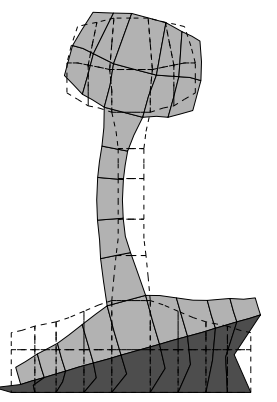

(c)

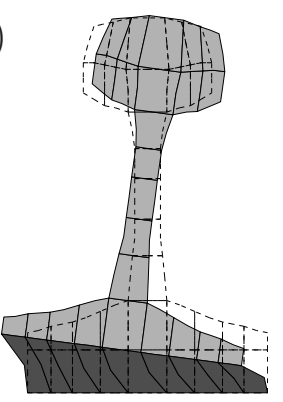

(f)

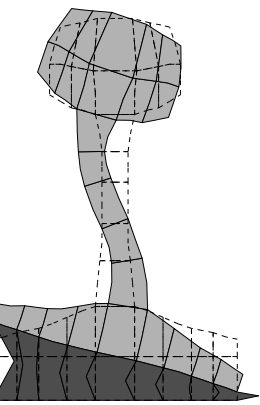

Fig. 9. Wave shapes at $k_{n}=1 \mathrm{rad} / \mathrm{m}$ : (a) Lateral bending wave, (b) Vertical bending wave, (c) Torsional wave, (d) Longitudinal wave, (e) Web bending wave 1, (f) Web bending wave 2 .

reads $[29]$

$$
\hat{\mathbf{U}}_{0}(x)=\sum_{n} A_{n}\left(\tilde{\mathbf{F}}_{0}\right) \tilde{\mathbf{U}}_{n} \mathrm{e}^{-\mathrm{i} k_{n} x},
$$


where the force vector $\tilde{\mathbf{F}}_{0}$ is formulated in the wavenumber domain. The expression for the amplitudes $A_{n}\left(\tilde{\mathbf{F}}_{0}\right)$ is given in [29].

For the predetermined lateral contact position on the rail (see Section 2.3), receptances are calculated from the result of Equation (6). Fig. 10 shows as examples the vertical and lateral point receptances and the vertical/lateral cross-receptance for the node at $y_{\mathrm{R}}=12 \mathrm{~mm}$ on the rail head. This node corresponds to the nominal simulation case in Section 3.

In the interaction model, the track is represented by a special type of Green's functions denoted moving Green's functions, $g_{i j, v}^{\mathrm{R}, x_{0}}(t)$, which include the motion of the nominal contact point along the rail $[28,30]$. The function $g_{i j, v}^{\mathrm{R}, x_{0}}(t)$ describes, for excitation of the rail (index $\mathrm{R}$ ) in $i$-direction at the position $x_{0}$ at time $t_{0}=0$, the displacement response of the rail in $j$-direction at a point moving with train speed $v$ away from the excitation, thus at the nominal contact point between wheel and rail. The discrete version of the moving Green's function $g_{i j, v}^{\mathrm{R}, x_{0}}(t)$ is constructed from (ordinary) Green's functions $g_{i j}^{\mathrm{R}, \mathrm{x}_{0}, \mathrm{x}_{0}+\alpha}(t)$, where the superscripts specify the excitation point $x_{0}$ and the response point $x_{0}+\alpha$ on the rail. The Green's functions $g_{i j}^{\mathrm{R}, \mathrm{x}_{0}, \mathrm{x}_{0}+\alpha}(t)$ are obtained from the corresponding track transfer receptances by inverse Fourier transform:

$$
g_{i j}^{\mathrm{R}, \mathrm{x}_{0}, \mathrm{x}_{0}+\alpha}(t)=\mathscr{F}^{-1}\left(G_{i j}^{\mathrm{R}, \mathrm{x}_{0}, \mathrm{x}_{0}+\alpha}(f)\right), \quad i, j=2,3 .
$$

The lateral and vertical displacements of the track at the contact point, $\xi_{2}^{\mathrm{R}}(t)$ and $\xi_{3}^{\mathrm{R}}(t)$, are calculated by convoluting the contact forces with the moving Green's functions

$$
\xi_{j}^{\mathrm{R}}(t)=\int_{0}^{t} \sum_{i=2}^{3} F_{i}(\tau) g_{v, i j}^{\mathrm{R}, v \tau}(t-\tau) \mathrm{d} \tau, \quad j=2,3 .
$$

In the case of the continuously supported track used in this article, the moving Green's functions are independent of the excitation position $x_{0}$ on the rail. Fig. 11 shows as example the moving Green's functions of the track obtained for excitation at the lateral contact position $y_{\mathrm{R}}=12 \mathrm{~mm}$ and a train speed $v=50 \mathrm{~km} / \mathrm{h}$. As the track is a waveguide and has in addition much higher damping than the wheel, it is well characterised by considerably shorter Green's functions than the wheel. The total length of the moving Green's functions taken into account is $0.25 \mathrm{~s}$.

\subsection{Contact position on wheel and rail}

Measured wheel and rail profiles are used in the wheel/rail interaction model. The wheel profile is a S1002 profile worn over $169000 \mathrm{~km}$. The rail profile is a 


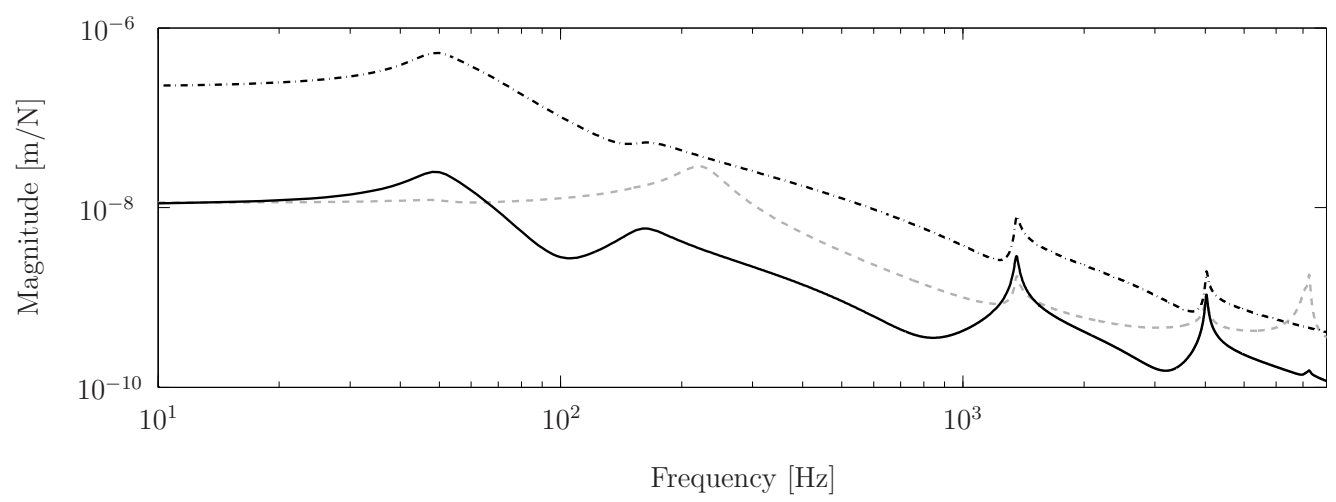

Fig. 10. Magnitudes of the track receptance at the rail head at $y_{\mathrm{R}}=12 \mathrm{~mm}:---$ (grey) vertical point receptance, $-\cdot-$ lateral point receptance, _- vertical/lateral cross-receptance.

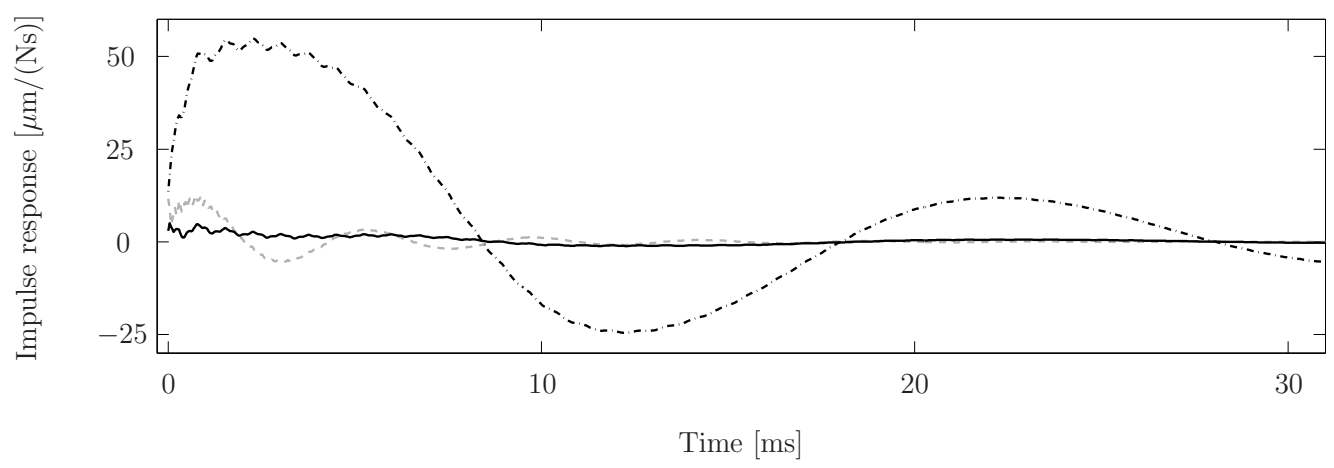

Fig. 11. Moving Green's functions of the track calculated for a lateral contact position on the rail $y_{\mathrm{R}}=12 \mathrm{~mm}$ and a train speed $v=50 \mathrm{~km} / \mathrm{h}:---$ (grey) vertical, - - - lateral, — vertical/lateral.

BV50 profile with inclination 1:40 measured at a curve in the network of Stockholm metro, where severe corrugation and squeal occur [31]. For these profiles, the contact points on wheel and rail have been determined as a function of the relative lateral displacement $\Delta y^{\mathrm{WR}}$ of the wheelset on the rail, with a preprocessor of the commercial vehicle-track interaction software GENSYS [32]. The roll angle of the wheelset and the deflection of the primary wheelset suspension for a chosen vertical preload $P$ of $65 \mathrm{kN}$ have been taken into account. Fig. 12 shows the results for the inner rail, which are used in the interaction model. For a given lateral displacement $\Delta y^{\mathrm{WR}}$, the actual profiles around the contact point on wheel and rail are considered in the algorithm. The wheel and track receptances calculated in the node closest to the contact point are used. The wheel and track receptances presented as examples in Sections 2.1 and 2.2 correspond to a relative lateral displacement of the wheelset on the rail of $-15 \mathrm{~mm}$. 


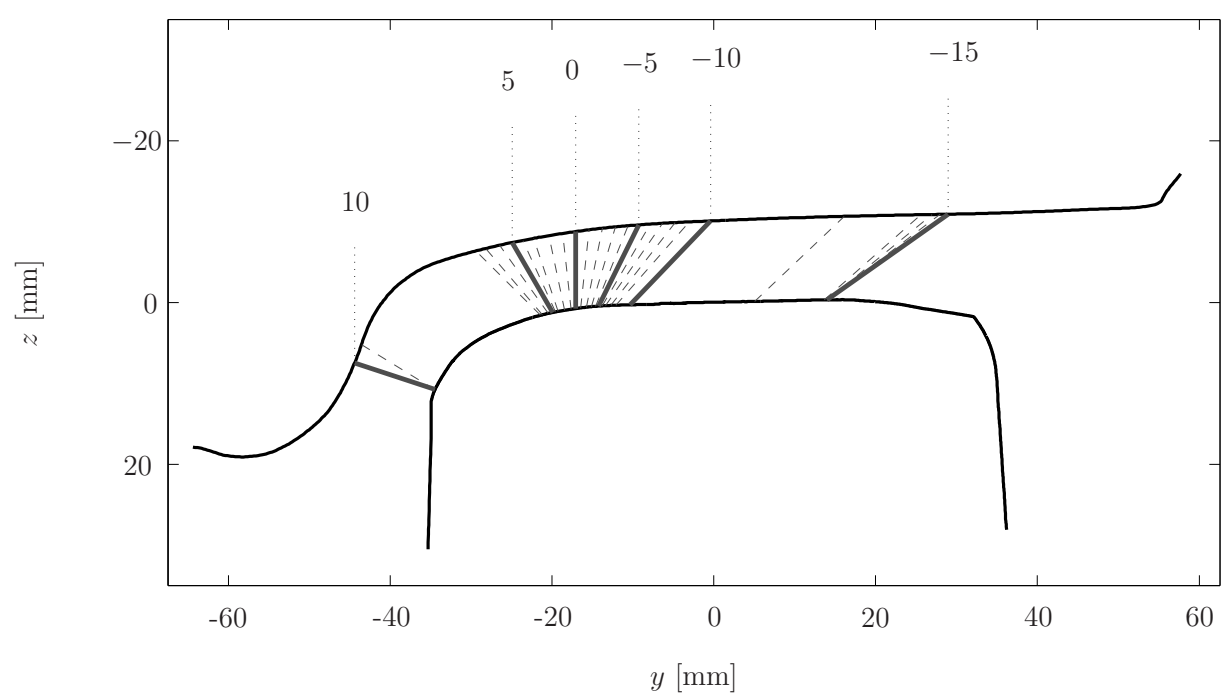

Fig. 12. Contact points for a worn wheel profile S1002 on a worn rail profile BV50 with inclination 1:40 calculated for different lateral displacements $\Delta y^{\mathrm{WR}}[\mathrm{mm}]$ of the wheelset on the rail; results given for $1 \mathrm{~mm}$ steps.

\subsection{Normal contact model}

The contact model is an implementation of Kalker's model CONTACT [33], which is a three-dimensional, non-steady state rolling contact model based on the assumption that wheel and rail can be locally approximated by elastic half-spaces. In addition to the parameters included in CONTACT, the contact model used in this article considers the combined roughness of wheel and rail on several parallel lines in the rolling direction and the contribution of the structural dynamics of wheel and rail to the creepage.

A potential contact area is introduced and divided into $N$ rectangular elements with side lengths $\Delta x$ and $\Delta y$ in $x$ - and $y$-directions, respectively. Assuming that wheel and rail are made of the same material, quasi-identity holds and, consequently, the normal and tangential contact problems can be solved separately [33].

The normal contact problem consists in determining which elements of the potential contact area are in contact, and calculating the local vertical displacement $u_{I 3}$ and the contact pressure $p_{I 3}$ in every element $I$.

The local vertical displacement, which is the displacement difference between rail and wheel,

$$
u_{I 3}=u_{I 3}^{\mathrm{R}}-u_{I 3}^{\mathrm{W}}, \quad I=1, \ldots, N,
$$


is related to the contact pressure according to

$$
u_{I 3}=\sum_{J=1}^{N} A_{I 3 J 3} p_{J 3}, \quad I=1, \ldots, N,
$$

where $A_{I 3 J 3}$ are influence coefficients for the elastic half-space, e.g. found in [33]. The total vertical contact force, $F_{3}$, is obtained by summing the contributions from the different elements:

$$
F_{3}=\sum_{I=1}^{N} p_{I 3} \Delta x \Delta y .
$$

Introducing the variable $d_{I}$ describing the distance between the deformed bodies in each element, the contact conditions are formulated as

$$
\begin{aligned}
d_{I} & \geq 0 \\
p_{I 3} & \geq 0 \\
d_{I} p_{I 3} & =0
\end{aligned} .
$$

If contact occurs in a surface element, the distance is zero and the contact pressure is positive. If contact does not occur, the distance is positive and the pressure is zero. Adhesion and penetration are excluded by Equation (12). The distance $d_{I}$ is obtained as

$$
d_{I}=-\delta+u_{I 3}+z_{I}^{\mathrm{R}}-z_{I}^{\mathrm{W}}+r_{I}^{\mathrm{R}}-r_{I}^{\mathrm{W}},
$$

where $z_{I}^{\mathrm{R}}$ and $z_{I}^{\mathrm{W}}$ are the profiles of rail and wheel, $r_{I}^{\mathrm{R}}$ and $r_{I}^{\mathrm{W}}$ are the roughness of rail and wheel, and $\delta$ is the approach of distant points

$$
\delta=\xi_{3}^{\mathrm{W}}-\xi_{3}^{\mathrm{R}} .
$$

The normal contact problem is solved with an active set algorithm [33].

\subsection{Tangential contact model}

In frictional rolling contact, the contact area is divided into a stick and a slip area. The tangential contact problem consists in determining which elements are in stick and in slip, and calculating the local tangential displacements $u_{I \tau}$ and tangential stresses $p_{I \tau}$ at the surface.

The relation between local tangential displacements and tangential stresses is given by

$$
u_{I \tau}=\sum_{\alpha=1}^{2} \sum_{J=1}^{N} A_{I \tau J \alpha} p_{J \alpha}, \quad \tau=1,2,
$$


where $A_{I \tau J \alpha}$ are influence coefficients for the elastic half-space, e.g. found in [33]. The tangential forces, $F_{\tau}$, are obtained by summing the contributions from the different elements:

$$
F_{\tau}=\sum_{I=1}^{N} p_{I \tau} \Delta x \Delta y, \quad \tau=1,2 .
$$

A contact element belongs to the stick area if the local shift, $S_{I \tau}$, vanishes:

$$
S_{I \tau}=0, \quad \tau=1,2 .
$$

Otherwise the contact element belongs to the slip area. The local shift, defined as the relative displacement of two opposing particles of the wheel and the rail with respect to each other in one time step $\Delta t=\Delta x / v$, is obtained as

$$
S_{I \tau}=u_{I \tau}+W_{\tau}^{*}-u_{I \tau}^{\prime}, \quad \tau=1,2 .
$$

The variable $u_{I \tau}^{\prime}$ represents the local displacement at the previous time step. In Kalker's formulation, $W_{I \tau}$ is the rigid shift calculated as

$$
\begin{aligned}
& W_{I 1}=(\xi-y \phi) \Delta x \\
& W_{I 2}=(\eta+x \phi) \Delta x,
\end{aligned}
$$

where $\xi, \eta$ and $\phi$ are the longitudinal, lateral and spin creepages. In this paper, the contribution of the structural dynamics of wheel and track is added to the rigid shift:

$$
\begin{aligned}
& W_{I 1}^{*}=W_{I 1} \\
& W_{I 2}^{*}=W_{I 2}+\left(\xi_{2}^{\mathrm{R}}-\xi_{2}^{\mathrm{W}}\right)-\left(\xi_{2}^{\prime \mathrm{R}}-\xi_{2}^{\prime \mathrm{W}}\right),
\end{aligned}
$$

where $\xi_{2}^{\prime \mathrm{R}}$ and $\xi_{2}^{\prime \mathrm{W}}$ are the lateral displacements of rail and wheel at the previous time step.

In the slip area, the following relations hold:

$$
\begin{aligned}
& \frac{p_{I \tau}}{\sqrt{p_{I 1}^{2}+p_{I 2}^{2}}}=-\frac{S_{I \tau}}{\sqrt{S_{I 1}^{2}+S_{I 2}^{2}}}, \quad \tau=1,2 \\
& p_{I 1}^{2}+p_{I 2}^{2}=\left(\mu p_{I 3}\right)^{2},
\end{aligned}
$$

where $\mu$ is the friction coefficient, which is assumed constant. Equation (23) ensures that the slip occurs in the direction opposite to the tangential stress. Equation (24) states that the tangential stress in the slip zone is equal to the traction bound $\mu p_{I 3}$.

The tangential contact problem is solved with an active set algorithm [33] combined with the Newton-Raphson method. 


\section{Simulation results}

In this section, the model described in Section 2 is applied to calculate highfrequency wheel/rail interaction during curving. First, the model is verified for quasi-static conditions. Second, dynamic calculations taking into account the wheel and track dynamics are carried out for different parameter combinations. If not stated differently in the text, the nominal parameters listed in Table 3 are used in the simulations. Given the coordinate system and the sign conventions used here, a negative value of the lateral creepage corresponds to an underradial position of the wheelset in the curve, which is a typical configuration for the leading wheelset of the bogie [34]. In an underradial position, the wheelset runs towards the outside of the curve with an angle of attack $\alpha>0$. This situation is illustrated in Fig. 13. The contrary case with $\alpha<0$ is called overradial position and corresponds to a positive value of the lateral creepage in the model. All simulations presented in this paper have been carried out for smooth wheel and rail surfaces. The inclination of the contact plane with regard to the horizontal plane has been neglected. Although the contact angle is small for the contact positions on the wheel tread/rail head, it should be noted that this simplification could influence the simulation results. Wheel flange/rail gauge corner contact has not been considered.

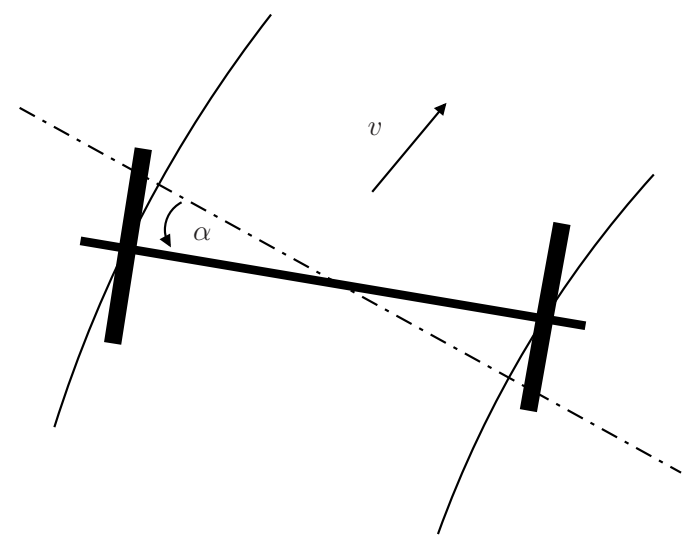

Fig. 13. Underradial position of the wheelset with angle of attack $\alpha>0$.

\subsection{Verification of the contact model against CONTACT}

Setting the wheel and track Green's functions to zero, i.e. assuming quasistatic conditions, makes it possible to verify the interaction model against Kalker's own implementation CONTACT of his variational theory of rolling contact $[33,35]$. As both models are implementations of the same theory, very similar results are expected. Differences can arise from the different solvers 
Table 3

Nominal simulation parameters

\begin{tabular}{ll}
\hline Train speed & $v=50 \mathrm{~km} / \mathrm{h}$ \\
Lateral displacement of wheel on rail & $\Delta y^{\mathrm{WR}}=-15 \mathrm{~mm}$ \\
Vertical static preload & $P=65 \mathrm{kN}$ \\
Longitudinal creepage & $\xi=0$ \\
Lateral creepage & $\eta=-1 \%$ \\
Spin creepage & $\phi=0$ \\
Friction coefficient & $\mu=0.3$ \\
Element length in $x$-direction & $\Delta x=0.5 \mathrm{~mm}$ \\
Element length in $y$-direction & $\Delta y=1 \mathrm{~mm}$ \\
Time step & $\Delta t=36 \mu \mathrm{s}$
\end{tabular}

used for the non-linear problem occurring in the tangential contact problem. CONTACT uses a specially designed Gauss-Seidel type solver [36], while a Newton-Raphson method is used in the present implementation. Furthermore, different tolerances and round-off practices can lead to slightly different results. Fig. 14 shows the division of the contact area into stick and slip zones obtained with both models using the parameters from Table 3 and an imposed lateral creepage of $\eta=-0.2 \%$. Rolling direction is the positive $x$-direction. Both

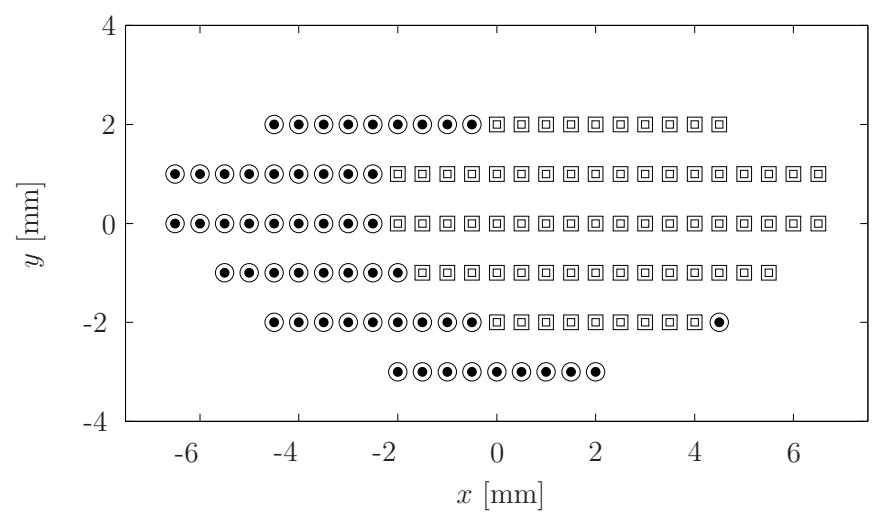

Fig. 14. Division of the contact zone: quasi-static case, $\eta=-0.2 \%$. Stick zone: $\square$ CONTACT, $\square$ interaction model; Slip zone: O CONTACT, $\bullet$ interaction model.

models give identical divisions of the contact zone. Wheel and track particles enter the contact zone at the leading edge and traverse the stick zone, before they reach the slip zone at the trailing edge of the contact. The corresponding distributions of the contact pressure and the total tangential stress are presented in Fig. 15. The tangential stress increases continuously from zero at the 
leading edge towards the slip zone, where it reaches the traction bound $\mu p_{3}$. The comparison of tangential stress and contact pressure obtained with both

(a)

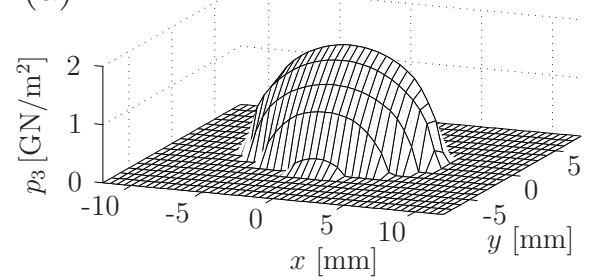

(b)

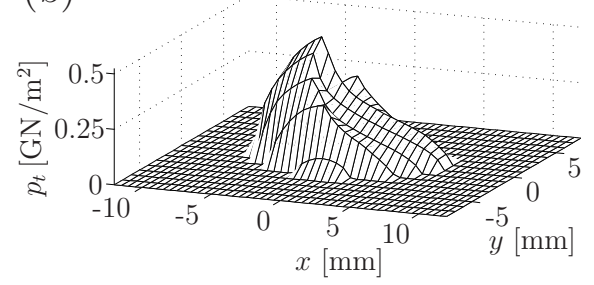

Fig. 15. Distribution of (a) contact pressure $p_{3}$ and (b) total tangential stress $p_{t}=\sqrt{p_{1}^{2}+p_{2}^{2}}$ in the contact zone: quasi-static case, $\eta=-0.2 \%$.

(a)

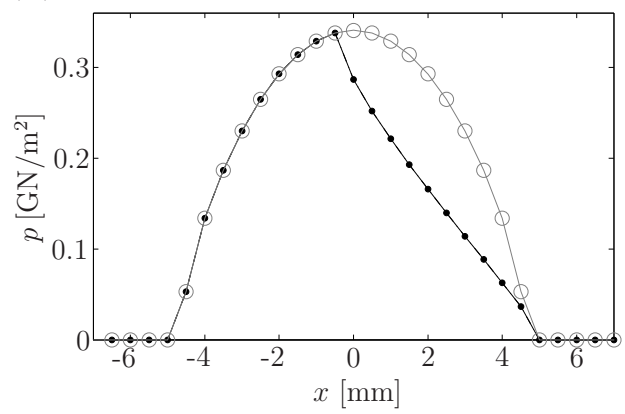

(b)

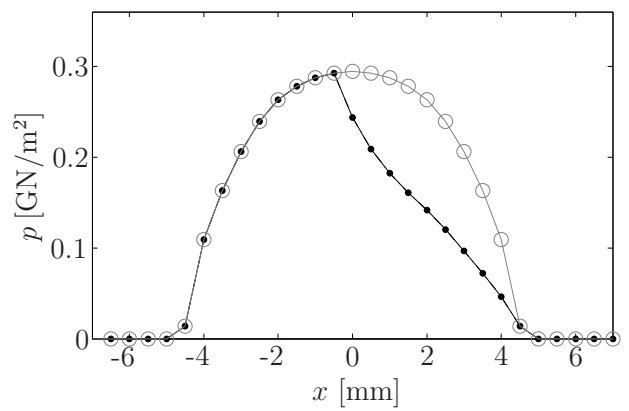

Fig. 16. Tangential stress $p_{t}$ (in black) and traction bound $\mu p_{3}$ (in grey) obtained with the interaction model $(-)$ in comparison to CONTACT $(\bullet / O)$ for the quasi-static case, $\eta=-0.2 \%$ : (a) on line $y=2 \mathrm{~mm}$, (b) on line $y=-2 \mathrm{~mm}$.

\subsection{Dynamic wheel/rail interaction}

The dynamic wheel/rail interaction during curving has been calculated for a range of different input parameters in order to investigate possible instabilities. In each simulation, the total simulated time is $3.5 \mathrm{~s}$. The preload and the creepages are applied gradually in the first $0.14 \mathrm{~s}$ of the simulation.

The time-domain simulations make it possible to determine the amplitude of occurring stick/slip oscillations. A problem is, however, that only a finite time interval is analysed and stick/slip oscillations that need a long time to build up are difficult to detect. Against this background, a measure $L_{F_{2}}$ based on the rms-value of the lateral contact force signal is introduced to characterise 
the relative instability of the simulations:

$$
L_{F_{2}}=20 \log \frac{F_{2, \mathrm{rms}}}{1 \mathrm{~N}} .
$$

The rms-value $F_{2, \text { rms }}$ of the transient part of the signal in a time period $T$ is obtained as

$$
F_{2, \mathrm{rms}}=\sqrt{\frac{1}{T} \int_{t_{1}}^{t_{1}+T}\left(F_{2}(t)-\bar{F}_{2}\right)^{2} \mathrm{~d} t},
$$

where $\bar{F}_{2}$ is the mean value of the force in the considered time interval. The rms-value is calculated from the last $0.15 \mathrm{~s}$ of the force signal, and only frequency components above $150 \mathrm{~Hz}$ are considered in order to exclude contributions from the wheel suspension. As the mean value is subtracted from the force signal, cases with no stick/slip, where the force approaches a constant value, give low values of $L_{F_{2}}$. Although sound radiation from the wheel has not been calculated, the measure $L_{F_{2}}$ based on the lateral contact force is also a good indicator for the likelihood of squeal to develop, - and to a certain degree - is an estimator for the strength of squeal.

In the simulation with the nominal parameters from Table 3, denoted simulation I, a pronounced stick/stick oscillation builds up. Fig. 17 presents the time series of the lateral contact force and Fig. 18 the corresponding power spectrum. The main frequency component in the spectrum (which, like all spectra presented in Section 3, has a frequency resolution of $6.8 \mathrm{~Hz}$ ) is identified as $434 \mathrm{~Hz}$, which is very close to the eigenfrequency of the $(2,0, \mathrm{a})$ mode of the wheel at $430 \mathrm{~Hz}$. Furthermore, the spectrum contains higher harmonics of this frequency. The measure $L_{F_{2}}$ according to Equation (25) is $47.0 \mathrm{~dB}$. Details of the stick/slip cycle are depicted in Figs. 19 and 20. During most of the cycle, the contact area is in full slip and the lateral contact force $F_{2}$ coincides with the traction limit $\mu F_{3}$. Only during a short phase in each cycle, partial stick occurs at the leading edge of the contact zone, see Fig. 20(b) and (c), and the lateral force takes a value below the traction bound.

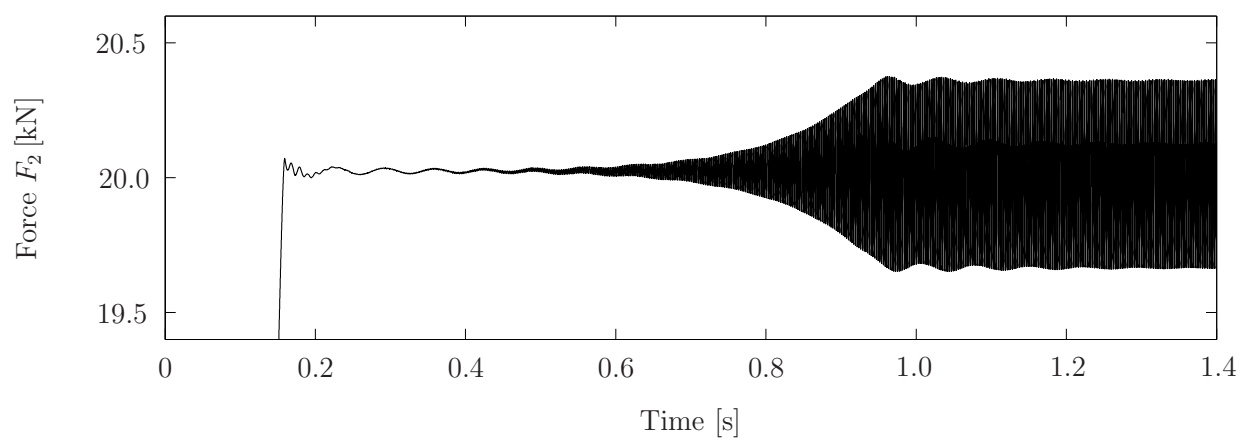

Fig. 17. Simulation I: time series of the lateral contact force $F_{2}$. 


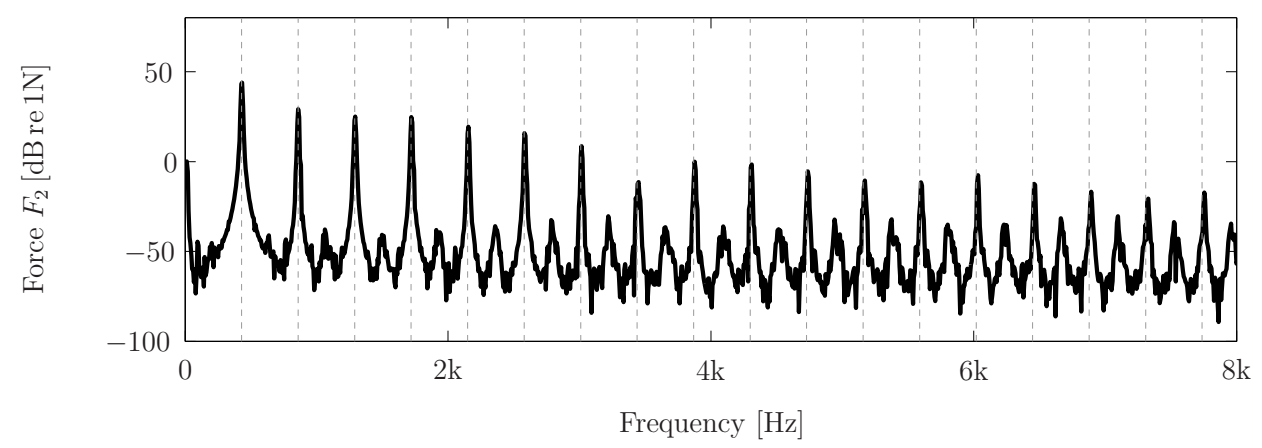

Fig. 18. Simulation I: power spectrum of the lateral contact force $F_{2}$. Multiples of the main frequency component at $434 \mathrm{~Hz}$ are indicated by vertical dashed lines.

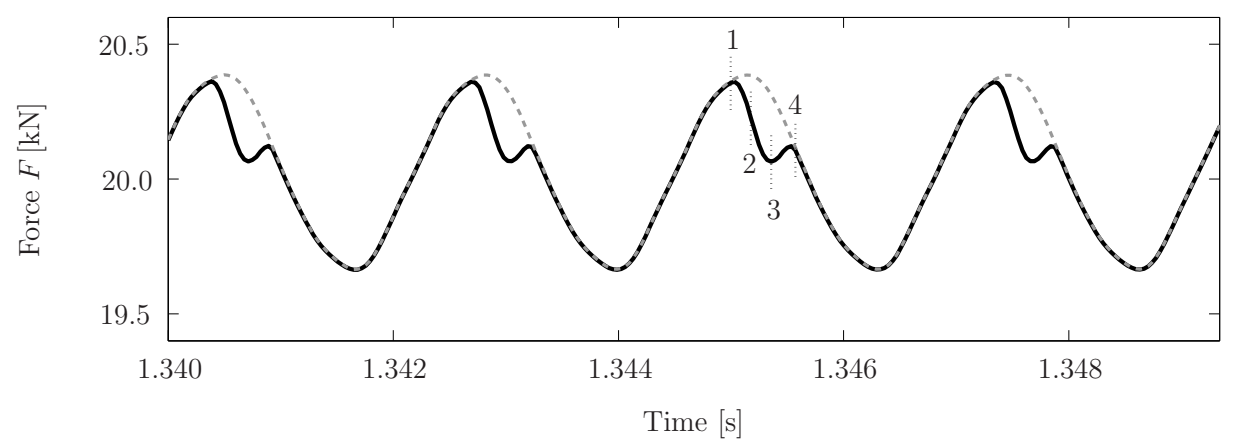

Fig. 19. Simulation I: zoom on time series of the contact forces; - lateral force $F_{2},---($ grey $)$ traction bound $\mu F_{3}$. The division of the contact zone at the time steps marked with Arabic numerals is depicted in Fig. 20.

(a)

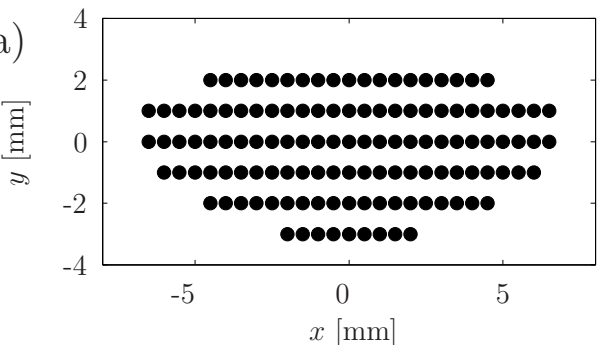

(c)

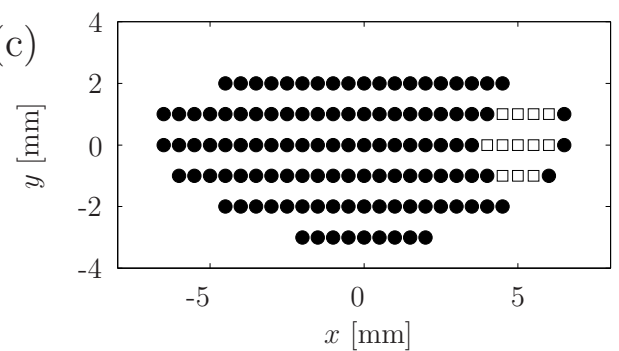

(b)

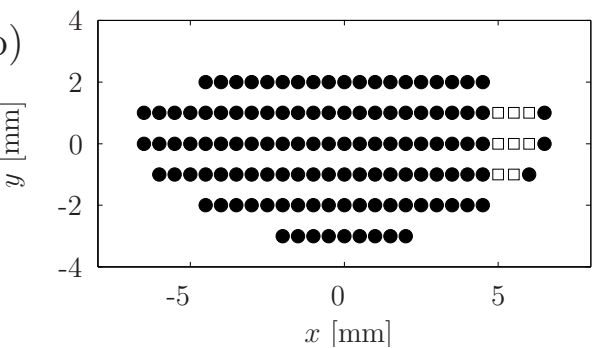

(d)

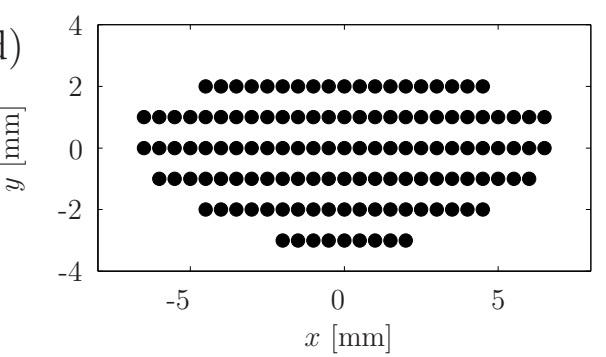

Fig. 20. Simulation I: division of contact zone in stick ( $\square)$ and slip (•) zones in the time steps marked in Fig. 19; (a) step 1, (b) step 2, (c) step 3, (d) step 4. 


\subsubsection{Influence of lateral creepage and friction coefficient}

The dynamic simulation I has been repeated for different values of lateral creepage and friction coefficient. The results are presented in Fig. 21 in terms of the measure $L_{F_{2}}$ calculated from the lateral force signal. Both parameters, the imposed lateral creepage and the friction coefficient, are seen to have a strong influence on the occurrence and amplitudes of stick/slip oscillations. High levels $L_{F_{2}}$ are only observed on the left side of Fig. 21 corresponding to negative values of the lateral creepage (i.e. underradial position of the wheelset in the curve). Another observation from Fig. 21 is that small changes in the parameters can lead to a sudden appearance (or disappearance) of pronounced stick/slip oscillations.

Simulations with $L_{F_{2}}>0 \mathrm{~dB}$, which have been denoted by Roman numerals in

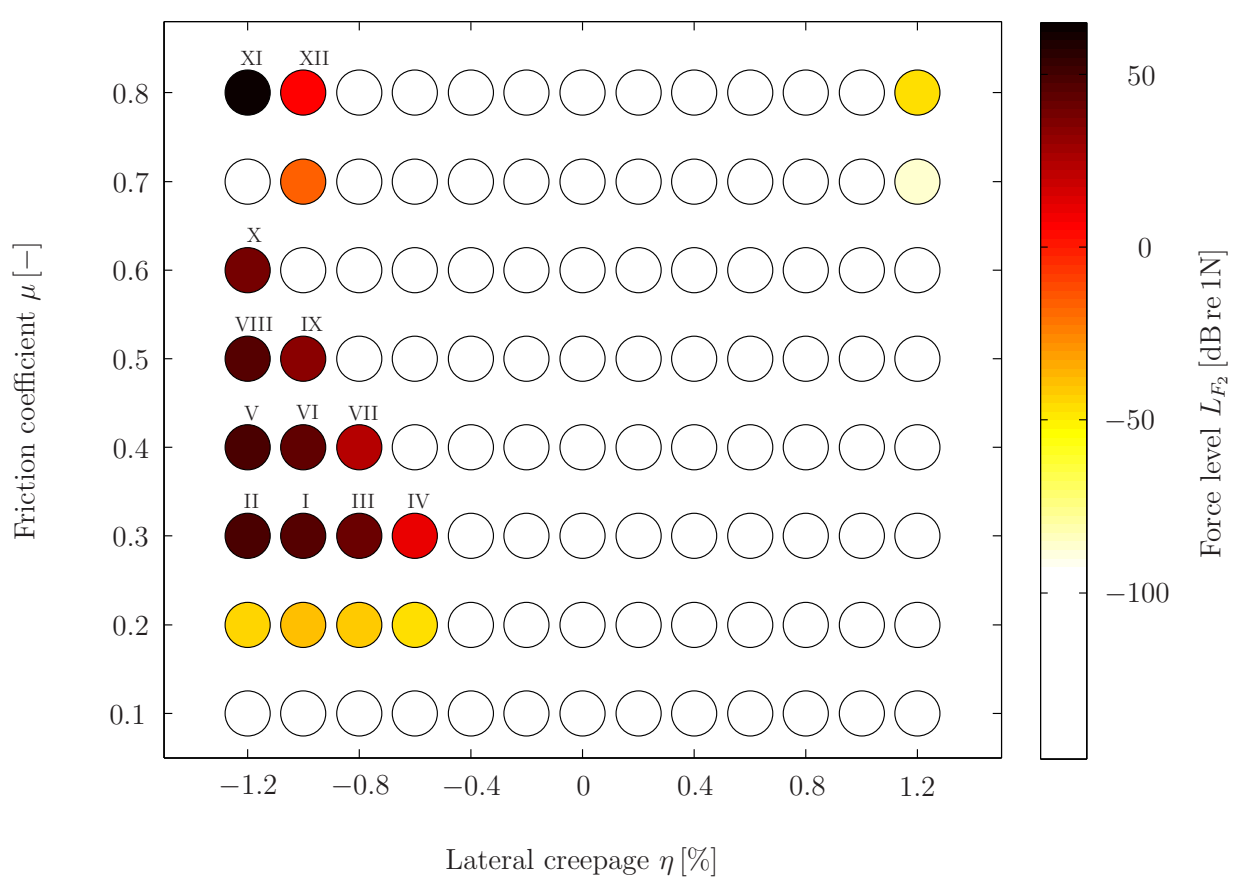

Fig. 21. Results of the dynamic simulations as function of the imposed lateral creepage $\eta$ and the friction coefficient $\mu$ : force level $L_{F_{2}}$ calculated according to Equation (25); simulations with $L_{F_{2}}>0 \mathrm{~dB}$ are denoted by Roman numerals.

Fig. 21, have been analysed in more detail. Among those, two groups can be identified according to the main frequency component; see the first two rows in Table 4. A third stick/slip frequency is found, when changing the lateral contact position; see Section 3.2.2 and Table 4. In the first group, which comprises simulations I-X, the main frequency component occurs at $434 \mathrm{~Hz}$, which corresponds to the $(2,0, a)$ mode of the wheel. This group has already been exemplified by the results of simulation I in Figs. 17 to 20. The second group consists of simulations XI and XII, where stick/slip develops at a frequency of 
$5235 \mathrm{~Hz}$. This frequency is close to the eigenfrequencies of the $(7,0, \mathrm{a})$ and $(2, \mathrm{c})$ modes of the wheel, which are $5216 \mathrm{~Hz}$ and $5228 \mathrm{~Hz}$, respectively. This second group of simulations is exemplified by the results from simulation XI presented in Figs. 22 to Fig. 25. The time signal of the lateral contact force (Fig. 22) reveals that the build-up of the stick/slip oscillation takes about three times as long as in the case of simulation I (Fig. 17). The change of mean value of the lateral force in Fig. 22 is explained by a lateral shift of the wheel on the rail. In the stick/slip oscillation of simulation XI, the lateral force stays below the traction limit $\mu F_{3}$ at all times (Fig. 24) and the division of the contact zone oscillates between the two extremes depicted in Fig. 25.

Table 4

Main frequency component in simulations with $L_{F_{2}}>0 \mathrm{~dB}$.

\begin{tabular}{lll}
\hline Frequency $[\mathrm{Hz}]$ & Closest wheel modes & Simulations \\
\hline 434 & $(2,0, \mathrm{a})$ & I-X, XIV \\
5235 & $(7,0, \mathrm{a}),(2, \mathrm{c})$ & XI, XII \\
1146 & $(3,0, \mathrm{a})$ & XIII \\
\hline
\end{tabular}

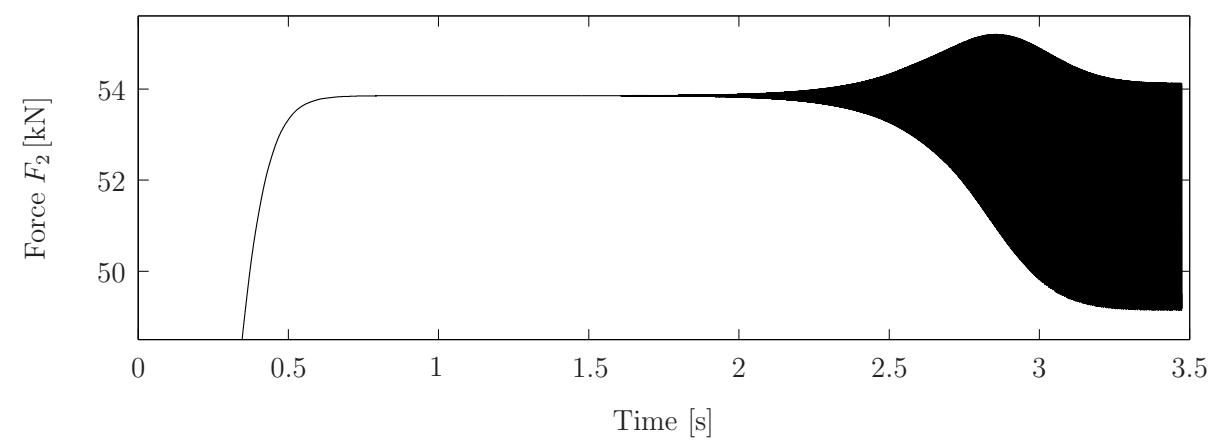

Fig. 22. Simulation XI: time series of the lateral contact force $F_{2}$.

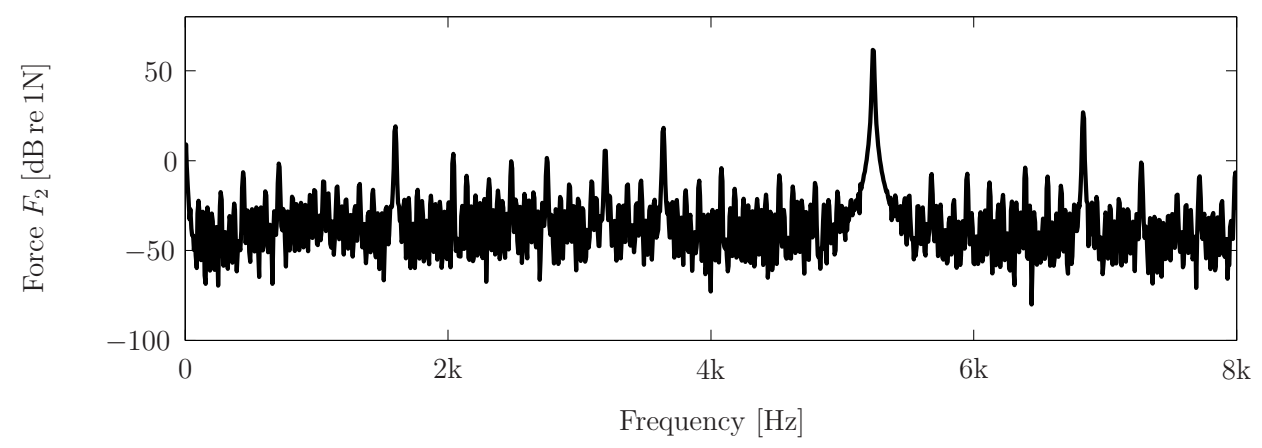

Fig. 23. Simulation XI: power spectrum of the lateral contact force $F_{2}$. 


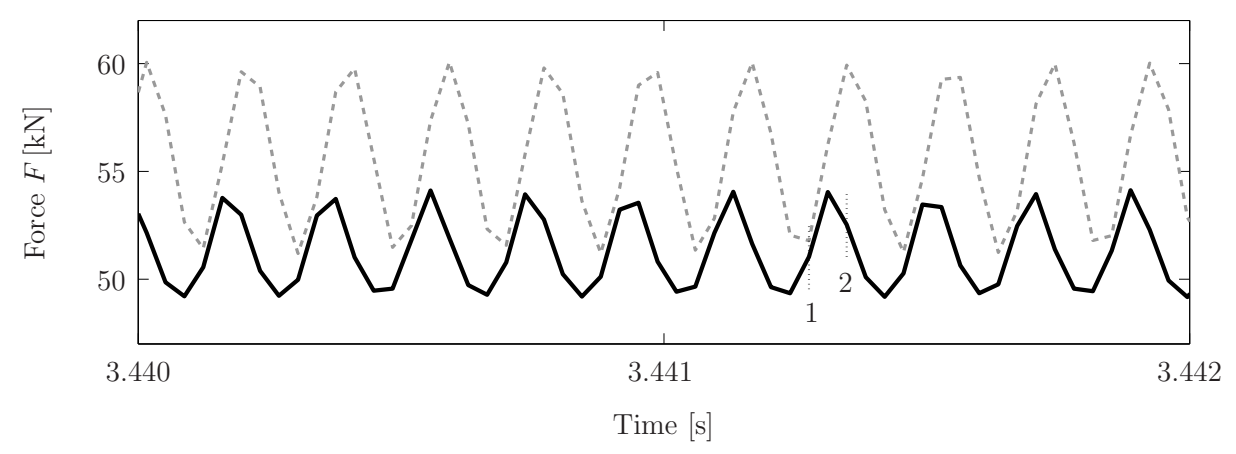

Fig. 24. Simulation XI: zoom on time series of the contact forces; - lateral force $F_{2},---($ grey $)$ traction bound $\mu F_{3}$. The division of the contact zone at the time steps marked with Arabic numerals is depicted in Fig. 25.
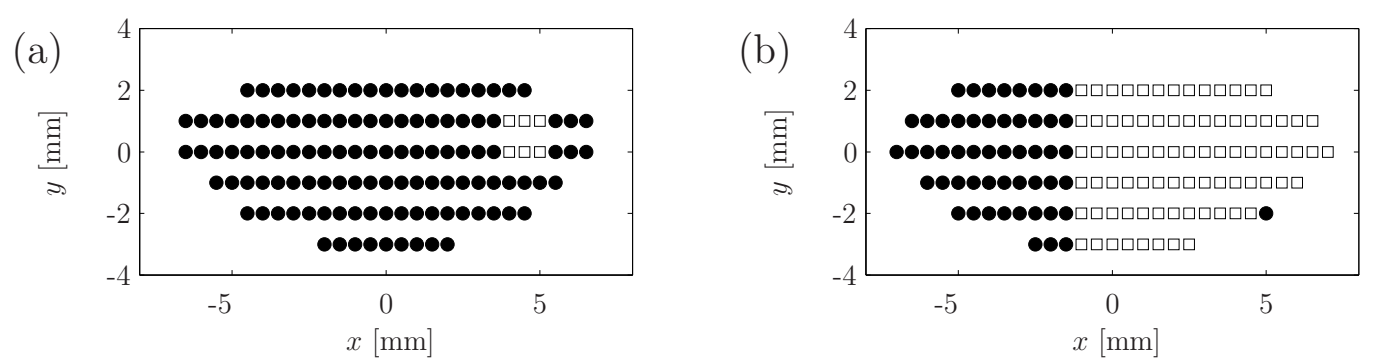

Fig. 25. Simulation XI: division of contact zone in stick $(\square)$ and slip $(\bullet)$ zones; (a) minimum size of the stick zone (corresponding to time step 1 in Fig. 24) and (b) maximum size of the stick zone (corresponding to time step 2 in Fig. 24).

\subsubsection{Influence of the lateral contact position}

Simulation I has also been repeated for four different values of the relative lateral displacement $\Delta y^{\mathrm{WR}}$ of the wheel on the rail (Fig. 26). In addition to simulation I, where $\Delta y^{\mathrm{WR}}$ is $-15 \mathrm{~mm}$, pronounced stick/slip oscillations occur also for $-10 \mathrm{~mm}$ (simulation XIII) and $-5 \mathrm{~mm}$ (simulation XIV), but not for $0 \mathrm{~mm}$ and $5 \mathrm{~mm}$, where the contact on the wheel tread occurs more towards the wheel flange (Fig. 12).

Simulation XIV belongs to the group of simulations with a main frequency component at $434 \mathrm{~Hz}$, while the stick/slip oscillation in simulation XIII occurs at $1146 \mathrm{~Hz}$, which corresponds to the $(3,0, \mathrm{a})$ mode of the wheel at $1143 \mathrm{~Hz}$. The results of simulation XIII are presented in Figs. 27 to 30. The stick/slip oscillation (Fig. 27) develops twice as fast as compared to simulation I (Fig. 17), and interacts initially with the initial oscillations of the wheel suspension. The first few higher harmonics in the power spectrum of the lateral contact force (Fig. 28) have similar magnitudes to the fundamental tone at $1146 \mathrm{~Hz}$. This 


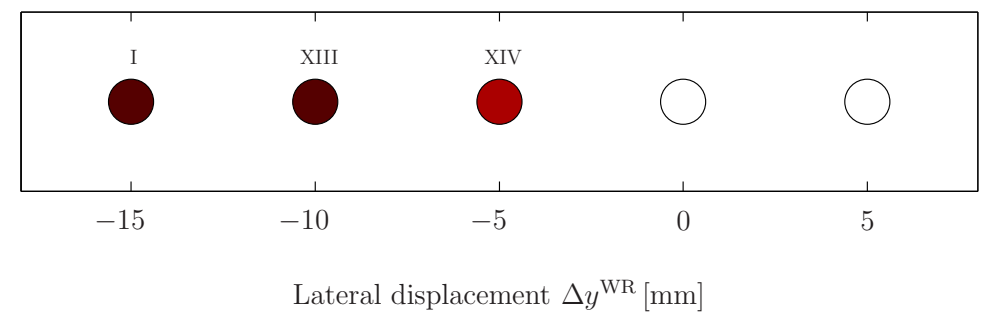

Fig. 26. Results of the dynamic simulations as function of the relative lateral displacement $\Delta y \mathrm{WR}$ of the wheel on the rail: force level $L_{F_{2}}$ according to Equation (25); simulations with $L_{F_{2}}>0 \mathrm{~dB}$ are denoted by Roman numerals. Colour bar as in Fig. 21.

highlights the strongly non-linear character of curve squeal. Remarkable in the case $\Delta y^{\mathrm{WR}}=-10 \mathrm{~mm}$ is the shape of the contact zone, which is split into three separate zones (Fig. 30).

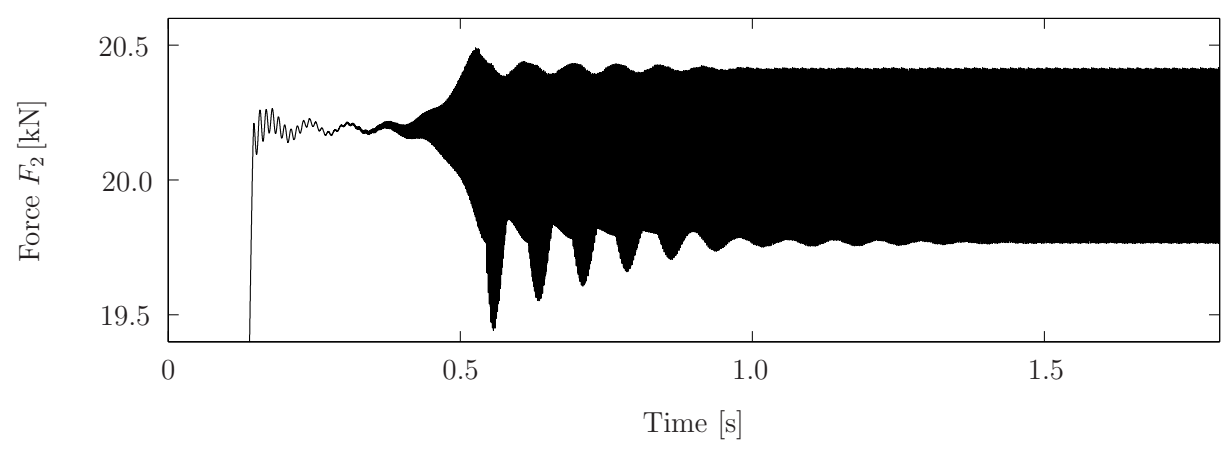

Fig. 27. Simulation XIII: time series of the lateral contact force $F_{2}$.

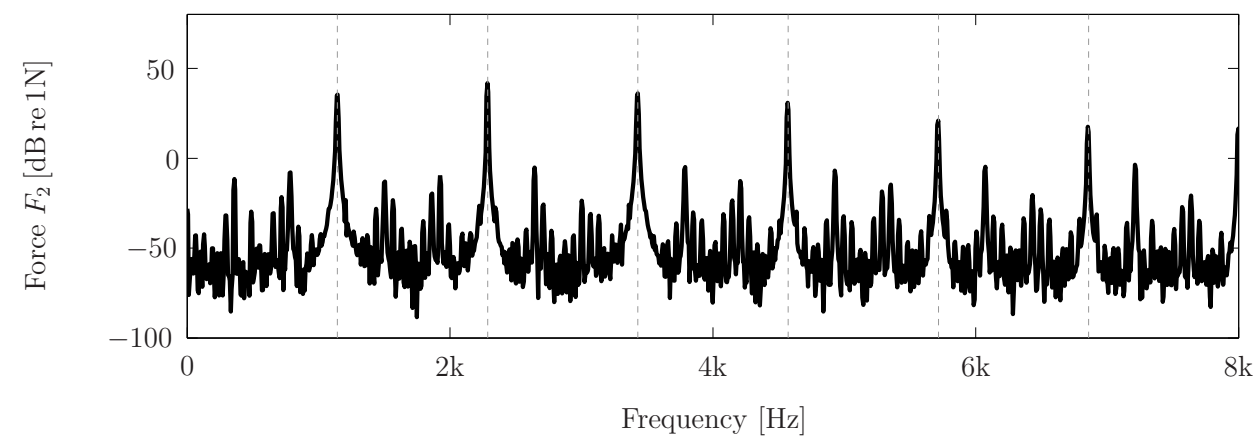

Fig. 28. Simulation XIII: power spectrum of the lateral contact force $F_{2}$. Multiples of the main frequency component at $1146 \mathrm{~Hz}$ are indicated by vertical dashed lines.

\subsection{Discussion}

The presented simulation results confirm that stick/slip during curving (and 


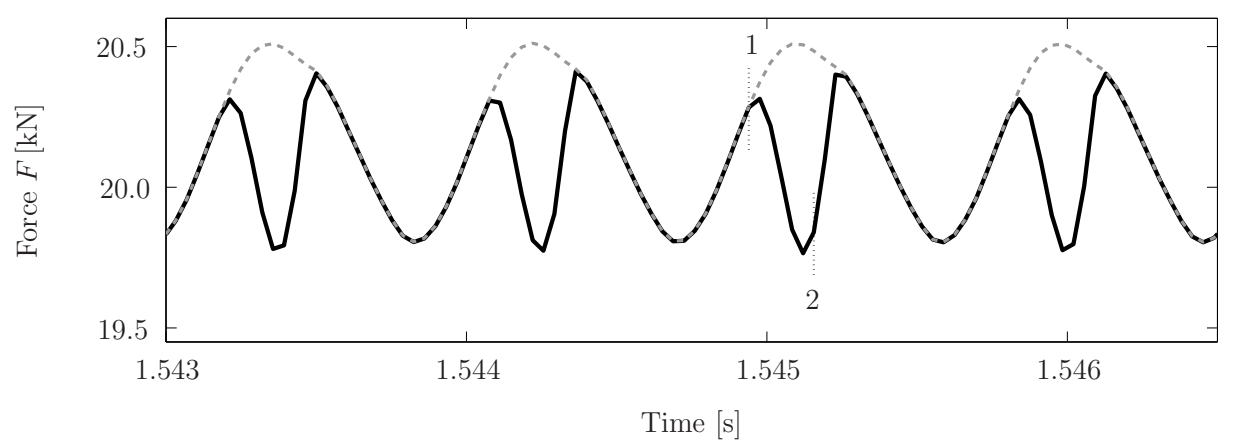

Fig. 29. Simulation XIII: zoom on time series of the contact forces; —- lateral force $F_{2},---($ grey $)$ traction bound $\mu F_{3}$. The division of the contact zone at the time steps marked with Arabic numerals is depicted in Fig. 30.
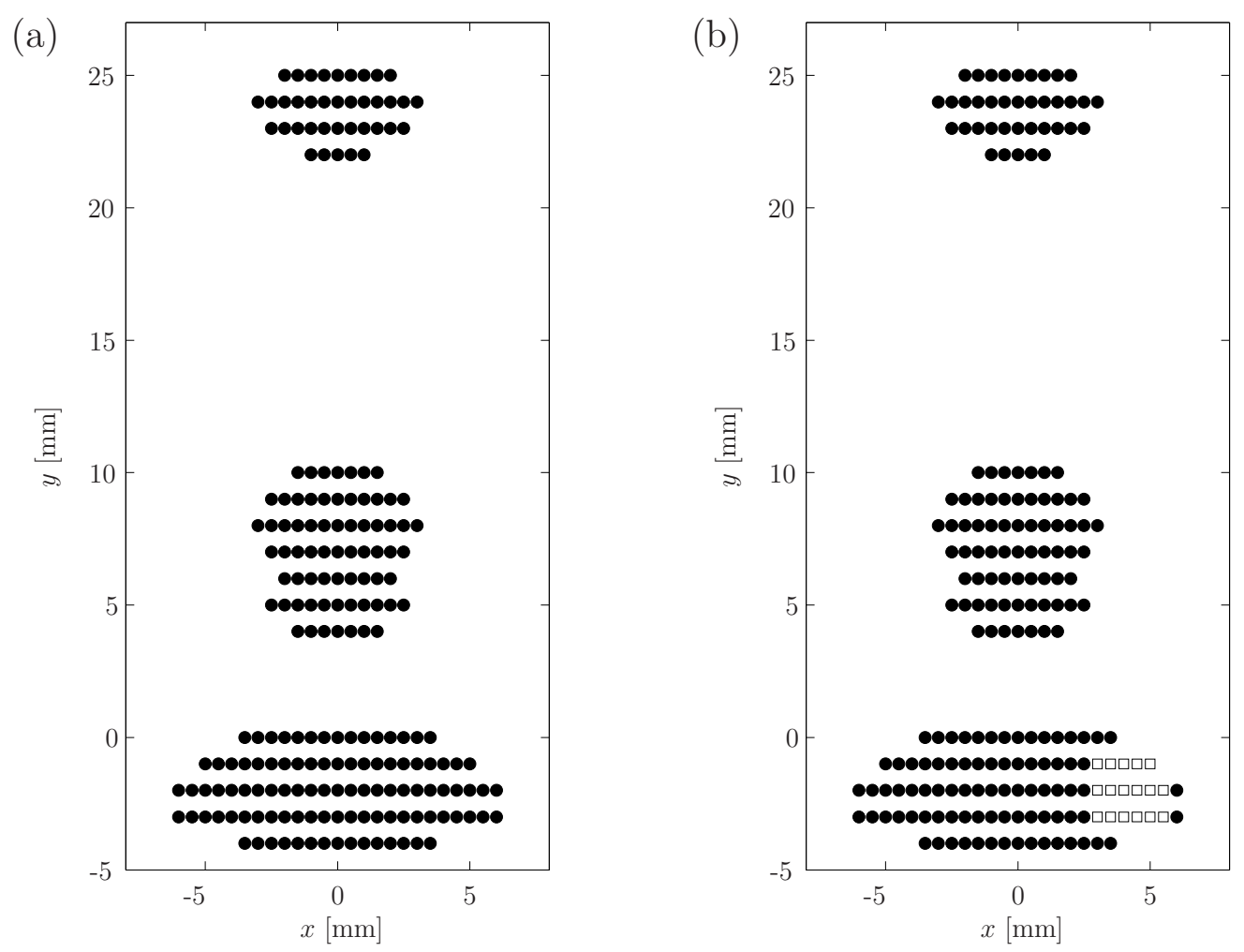

Fig. 30. Simulation XIII: division of contact zone in stick $(\square)$ and slip $(\bullet)$ zones; (a) minimum size of the stick zone (full slip corresponding to time step 1 in Fig. 29) and (b) maximum size of the stick zone (corresponding to time step 2 in Fig. 29).

coefficient, but also in the case of constant friction. The occurrence of stick/slip is attributed to the coupling between vertical and tangential dynamics. The time-domain simulations, however, give only limited insight into the precise underlying mechanism. In the case of stick/slip at $5235 \mathrm{~Hz}$, two wheel modes, the axial $(7,0, a)$ mode and the circumferential $(2, c)$ mode, could be shown to 
participate. If any of the two modes is assigned a very high modal damping ratio (e.g. 1), the stick/slip oscillation ceases to exist. For stick/slip at $434 \mathrm{~Hz}$ and $1146 \mathrm{~Hz}$, only one mode could be shown to participate in each case, which is respectively the $(2,0, a)$ axial mode and the $(3,0, a)$ axial mode. In these two cases, the elimination of neighbouring modes from the frequency response function of the wheel did not have any influence on the stick/slip oscillation.

The validity of the simulations presented is limited by the model assumptions. The surface roughness of wheel and rail (which could be included as described in Section 2.4) and the slight inclination of the contact plane have not been considered. Both simplifications could influence the occurrence of stick/slip oscillations. It has been assumed that the lateral creepage and the lateral contact position do not change during the simulation, which is a reasonable assumption for quasi-static curving only. Furthermore, the friction coefficient was assumed to remain constant along the track, which is a questionable assumption for real conditions.

The simulation results are, however, in good qualitative agreement with general observations about squeal noise and results reported in the literature. Squeal is known to occur predominantly at frequencies corresponding to axial modes of the wheel with zero nodal circles $(m=0)$ [1], which agrees with what is found here. The parameters investigated - the lateral creepage, the lateral contact position and the frictional properties - are key parameters for the occurrence of curve squeal $[1,37]$ and they show a significant influence on the simulation results presented. de Beer et al. [8] found in a laboratory test that squeal occurs only above a threshold value of the angle of attack (i.e. the lateral creepage). This behaviour is clearly reflected in the results of Fig. 21. Based on the model of de Beer [8], Thompson [1] reports that squeal is most likely to occur if the contact on the wheel tread occurs towards the field side of the tread. The same result is seen in Fig. 26. Finally the results from Fig. 21, where pronounced stick/slip does not occur below friction values of 0.3 , also agree with the well-known fact that low friction conditions (wet weather, lubrication) reduce the likelihood of squeal.

\section{Conclusions}

In this paper, a detailed time-domain model for the dynamic wheel/rail interaction was proposed. In order to keep computational effort in the wheel/rail interaction model as low as possible, vehicle and track were represented by impulse response functions derived from detailed FE models, which are calculated in advance. As contact model a transient, three-dimensional and nonlinear contact model has been implemented based on Kalker's theory.

The implementation of the contact model has been validated for quasi-static 
conditions against Kalker's implementation CONTACT and showed very good agreement.

One essential feature of the simulation model is that the coupling between normal and tangential directions is taken into account. This was a main condition for being able to investigate the occurrence of squeal for constant friction values instead of falling friction curves.

In the rather limited parameter study presented in this paper, certain cases could be identified where strong unstable tangential contact forces appeared. In all cases, the exhibiting frequencies were close to wheel resonances corresponding to axial modes of the wheel with zero nodal circles $(m=0)$. In this study, the lateral creepage, the lateral contact position and the frictional properties proved to be key parameters for the occurrence of curve squeal. In general, it was found that the conditions prevailing at the leading inner wheel (underradial position, contact towards field side of tread) promote squeal. All these findings are in good qualitative agreement with previously published findings on curve squeal.

In addition, the simulation results show that squeal can be observed even for a constant friction coefficient as suggested by previous publications.

Although the results shown in this paper are samples rather than due to an exhaustive parameter study, the results are promising and suggest that the model might be a good tool for carrying out well-controlled numerical experiments in order to increase the understanding of the mechanisms behind curve squeal. Especially noteworthy is that the model allows more realistic simulations taking into account the roughness of the wheel and rail running surfaces. However, for simulating real situations and perhaps even using such cases for validation, a better knowledge of the friction characteristics in the field is needed.

\section{Acknowledgements}

This work was performed as part of the activities within the Centre of Excellence CHARMEC (CHAlmers Railway MEChanics). I am grateful for advice and help by Prof. Wolfgang Kropp (CHARMEC, Chalmers University of Technology) with the development of the wheel/rail interaction model. I would like to thank Prof. David Thompson (ISVR, University of Southampton) and Dr. Briony Croft (former PhD student at ISVR) for supplying me with the wheel model used in this paper. Furthermore, the access to the Wave Guide Finite Element toolbox WANDS (developed by the Dynamics Group at ISVR), which I used for the modelling of the track, is greatly acknowledged. Finally, I would like to thank Dr. Peter Torstensson (CHARMEC, Chalmers University of Technology) for carrying out the GENSYS calculations. 


\section{References}

[1] D. Thompson, Railway Noise and Vibration: Mechanisms, Modelling and Means of Control, Elsevier, Oxford, UK, 2009.

[2] M.J. Rudd, Wheel/rail noise - part II: Wheel squeal, Journal of Sound and Vibration 46 (3) (1976) 381-394.

[3] H. Stappenbeck, Das Kurvengeräusch der Straßenbahn - Möglichkeiten zu seiner Unterdrückung (The curve noise of the tramway - possibilities of its suppression), VDI Zeitschrift, 96 (6) (1954) 171-175.

[4] U. Fingberg, A model for wheel-rail squealing noise, Journal of Sound and Vibration, 143 (1990) 365-377.

[5] F. J. Périard, Wheel-Rail Noise Generation: Curve squealing by trams, PhD thesis, TU Delft, 1998.

[6] M.A. Heckl, I.D. Abrahams, Curve squeal of train wheels, part 1: Mathematical model for its generation, Journal of Sound and Vibration 229 (3) (2000) 669693.

[7] M.A. Heckl, Curve squeal of train wheels, part 2: Which wheel modes are prone to squeal? Journal of Sound and Vibration 229 (3) (2000) 695-707.

[8] F.G. de Beer, M.H.A. Janssens, P.P. Kooijman, Squeal noise of rail-bound vehicles influenced by lateral contact position. Journal of Sound and Vibration 267 (2003) 497-507.

[9] O. Chiello, J.-B. Ayasse, N. Vincent, J.-R. Koch, Curve squeal of urban rolling stock - part 3: Theoretical model, Journal of Sound and Vibration 293 (2006) 710-727.

[10] J.F. Brunel, P. Dufrénoy, M. Naït, J.L. Muñoz, and F. Demilly, Transient model for curve squeal noise, Journal of Sound and Vibration 293 (2006) 758-765.

[11] G. Xie, P.D. Allen, S.D. Iwnicki, A. Alonso, D.J. Thompson, C.J.C. Jones, Z.Y. Huang, Introduction of falling friction coefficients into curving calculations for studying curve squeal noise, Vehicle System Dynamics 44 (Supplement) (2006) 261-271.

[12] P.J. Remington, Wheel/rail squeal and impact noise: What do we know? What don't we know? Where do we go from here?, Journal of Sound and Vibration 116 (2) (1985) 339-353.

[13] W. Lang, G. Roth, Optimale Kraftschlußausnutzung bei HochleistungsSchienenfahrzeugen (Optimal utilisation of adhesion for high-performance rail vehicles), Eisenbahntechnische Rundschau 42 (1993) 61-66.

[14] O. Polach, Creep forces in simulations of traction vehicles running on adhesion limit, Wear 258 (2005) 992-1000. 
[15] A.D. Monk-Steel, D.J. Thompson, F.G. de Beer, M.H.A. Janssens, An investigation into the influence of longitudinal creepage on railway squeal noise due to lateral creepage, Journal of Sound and Vibration 293 (2006) 766-776.

[16] X. Liu, Meehan P.A., Investigation of the effect of lateral adhesion and rolling speed on wheel squeal noise, Proceedings of the Institution of Mechanical Engineers, Part F: Journal of Rail and Rapid Transit 227(5) (2013) 469-480.

[17] J.T. Oden and J.A.C. Martins, Models and computational methods for dynamic friction phenomena, Computer Methods in Applied Mechanics and Engineering 52 (1985) 527-634.

[18] N. Hoffmann, M. Fischer, R. Allgaier, L. Gaul, A minimal model for studying properties of the mode-coupling type instability in friction induced oscillations, Mechanics Research Communications 29 (2002) 197-205.

[19] Ch. Glocker, E. Cataldi-Spinola, R.I. Leine, Curve squealing of trains: Measurement, modelling and simulation, Journal of Sound and Vibration 324 (2009) 365-386.

[20] Y. Ben Othman, Kurvenquietschen: Untersuchung des Quietschvorgangs und Wege der Minderung (Curve squeal: Investigation of the squeal process and ways of mitigation), PhD thesis, TU Berlin, 2009.

[21] J.R. Koch, N. Vincent, H. Chollet, O. Chiello, Curve squeal of urban rolling stock - part 2: Parametric study on a 1/4 scale test rig. Journal of Sound and Vibration 293 (2006) 701-709.

[22] J. Jiang, D. Anderson, R.Dwight, The mechanisms of curve squeal, Proceedings of the 11th International Workshop on Railway Noise (IWRN 11), pp.655-662, September 9-13, 2013, Uddevalla, Sweden.

[23] Z.Y. Huang, D.J. Thompson, C.J.C. Jones, Squeal prediction for a bogied vehicle in a curve, in: B. Schulte-Werning et al. (Eds.), Noise and Vibration Mitigation for Rail Transportation Systems, NNFM 99, Springer-Verlag, Berlin, Heidelberg, 2008, pp. 313-319.

[24] J.J. Kalker, A fast algorithm for the simplified theory of rolling contact, Vehicle System Dynamics, 11 (1982) 1-13.

[25] F. Wullens, W. Kropp, A three dimensional contact model for tyre/road interaction in rolling conditions, Acta Acustica united with Acustica, 90 (4) (2004) 702-711.

[26] A. Pieringer, W. Kropp, D.J. Thompson, Investigation of the dynamic contact filter effect in vertical wheel/rail interaction using a 2D and a 3D non-Hertzian contact model, Wear 271 (1-2) (2010) 328-338.

[27] A. Pieringer, W. Kropp, A time-domain model for coupled vertical and tangential wheel/rail interaction - a contribution to the modelling of curve squeal, in: T. Maeda et al. (Eds.), Noise and Vibration Mitigation for Rail Transportation Systems, NNFM 118, Springer, 2012, pp.221-229. 
[28] A. Pieringer, Time-domain modelling of high-frequency wheel/rail interaction, PhD thesis, Chalmers University of Technology, Göteborg, Sweden, 2011.

[29] C.-M. Nilsson, C.J.C. Jones, D.J. Thompson, J. Ryue, A waveguide finite element and boundary element approach to calculating the sound radiated by railway and tram rails, Journal of Sound and Vibration 321 (2009) 813-836.

[30] A. Nordborg, Wheel/rail noise generation due to nonlinear effects and parametric excitation, Journal of the Acoustical Society of America 111 (4) (2002) 1772-1781.

[31] P.T. Torstensson, J.C.O. Nielsen, Monitoring of rail corrugation growth due to irregular wear on a railway metro curve. Wear 267 (2009) 556-561).

[32] DEsolver, GENSYS users manual, 2009.

[33] J.J. Kalker, Three-Dimensional Elastic Bodies in Rolling Contact, Kluwer Academic Publishers, Dordrecht, Boston, London, 1990.

[34] E. Andersson, M. Berg, S. Stichel, Rail Vehicle Dynamics, Lecture Notes, KTH Stockholm, 2007.

[35] E.A.H. Vollebregt, User' s Guide for CONTACT, J.J. Kalker's variational contact model, Technical Report, TR09_03, version 0.9, VORtech Computing, Delft, The Netherlands, 2009.

[36] E.A.H. Vollebregt, A Gauss-Seidel type solver for special convex programs, with application to frictional contact mechanics, Journal for Optimization Theory and Applications, 87 (1) (1995) 47-67.

[37] N. Vincent, J.R. Koch, H. Chollet, J.Y. Guerder, Curve squeal of urban rolling stock - part 1: State of the art and field measurements, Journal of Sound and Vibration 293 (2006) 691-700. 